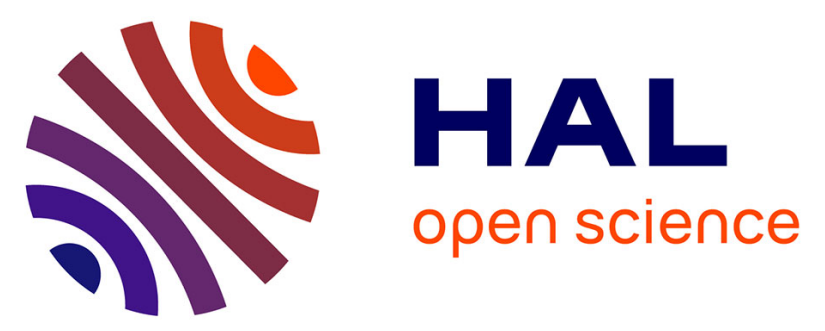

\title{
Oxylipin regulation by phenolic compounds from coffee beverage: Positive outcomes from a randomized controlled trial in healthy adults and macrophage derived foam cells
}

Oscar J. Lara-Guzmán, Sonia Medina, Rafael Alvarez, Camille Oger, Thierry Durand, Jean-Marie Galano, Natalia Zuluaga, Ángel Gil-Izquierdo, Katalina Muñoz-Durango

\section{To cite this version:}

Oscar J. Lara-Guzmán, Sonia Medina, Rafael Alvarez, Camille Oger, Thierry Durand, et al.. Oxylipin regulation by phenolic compounds from coffee beverage: Positive outcomes from a randomized controlled trial in healthy adults and macrophage derived foam cells. Free Radical Biology and Medicine, 2020, 160, pp.604-617. 10.1016/j.freeradbiomed.2020.07.020 . hal-03115352

\author{
HAL Id: hal-03115352 \\ https://hal.science/hal-03115352
}

Submitted on 19 Jan 2021

HAL is a multi-disciplinary open access archive for the deposit and dissemination of scientific research documents, whether they are published or not. The documents may come from teaching and research institutions in France or abroad, or from public or private research centers.
L'archive ouverte pluridisciplinaire HAL, est destinée au dépôt et à la diffusion de documents scientifiques de niveau recherche, publiés ou non, émanant des établissements d'enseignement et de recherche français ou étrangers, des laboratoires publics ou privés. 


\title{
Oxylipin regulation by phenolic compounds from coffee beverage: Positive outcomes from a randomized controlled trial in healthy adults and macrophage derived foam cells
}

\author{
Oscar J. Lara-Guzmán ${ }^{\mathrm{a}}$, Sonia Medina ${ }^{\mathrm{b}}$, Rafael Álvarez ${ }^{\mathrm{c}, 1}$, Camille Oger ${ }^{\mathrm{d}}$, Thierry Durand ${ }^{\mathrm{d}}$, \\ Jean-Marie Galano $^{\mathrm{d}}$, Natalia Zuluaga ${ }^{\mathrm{a}, 2}$, Ángel Gil-Izquierdo ${ }^{\mathrm{b}, * *}$, Katalina Muñoz-Durango, ${ }^{\mathrm{a}, *}$ \\ ${ }^{a}$ Vidarium - Nutrition, Health and Wellness Research Center, Nutresa Business Group, Calle 8 Sur No. 50-67, Medellín, Colombia \\ ${ }^{\mathrm{b}}$ Research Group on Quality, Safety and Bioactivity of Plant Foods, Department of Food Science and Technology, CEBAS (CSIC), P.O. Box 164, 30100 Campus University \\ Espinardo, Murcia, Spain \\ ${ }^{c}$ Grupo de Investigación en Sustancias Bioactivas, Facultad de Ciencias Farmacéuticas y Alimentarias, Universidad de Antioquia, Calle 70 No. 52-21, Medellín, Colombia \\ d Institut des Biomolécules Max Mousseron (IBMM), UMR 5247, CNRS, University of Montpellier, ENSCM, Faculty of Pharmacy, Montpellier, France
}

Oxylipins are considered biomarkers related to cardiovascular diseases (CVDs). They are generated in vivo via the oxygenation of polyunsaturated fatty acids as a result of oxidative stress and inflammation. Oxylipins are involved in vascular functions and are produced during foam cell formation in atherogenesis. Additionally, the consumption coffee is associated with the regulation on a particular oxylipin group, the $\mathrm{F}_{2 \mathrm{t}^{-}}$-isoprostanes $\left(\mathrm{F}_{2 \mathrm{t}^{-}}\right.$ IsoPs). This function has been attributed to the chlorogenic acids (CGAs) from the coffee beverage. Considering the anti-inflammatory and antioxidant properties of CGAs, we evaluated the effects of two types of coffee that provided $787 \mathrm{mg}$ CGAs/day (Coffee A) and $407 \mathrm{mg}$ CGAs/day (Coffee B) by reducing 35 selected oxylipins in healthy subjects. Furthermore, we assessed the effect of CGAs on the cellular proatherogenic response in foam cells by using an oxidized LDL (oxLDL)-macrophage interaction model. After eight weeks of coffee consumption, the contents of 12 urine oxylipins were reduced. However, the effect of Coffee A showed a stronger decrease in IsoPs, dihomo-IsoPs, prostaglandins (PGs) and PG metabolites, probably due to its higher content of CGAs. Neither of the two coffees reduced the levels of oxLDL. Moreover, the in vitro oxylipin induction by oxLDL on foam cells was ameliorated by phenolic acids and CGAs, including the inhibition of IsoPs and PGs by caffeoylquinic and dicaffeoylquinic acids, respectively, while the phenolic acids maintained both antioxidant and anti-inflammatory activities. These findings suggest that coffee antioxidants are strong regulators of oxylipins related to CVDs. The clinical trial was registered on the International Clinical Trials Registry Platform, WHO primary registry (RPCEC00000168).

Keywords:

Coffee beverage

Chlorogenic acids

Oxylipins

oxLDL

Macrophage foam cells.

\section{Introduction}

Current protocols related to the screening and treatment of atherosclerosis do not consider reducing the lipid peroxidation of polyunsaturated fatty acids (PUFAs) but are more focused on cholesterol levels in lipoproteins [1]. The enzymatic and nonenzymatic oxidation of PUFAs, such as arachidonic, eicosapentaenoic, docosahexaenoic, dihomo gamma linolenic and adrenic acids, generate oxylipins: prostaglandins (PGs) and prostanoid-like molecules such as isoprostanoids (isoprostanes (IsoPs), dihomo-isoprostanes (dihomo-IsoPs) and neuroprostanes (NeuroPs)), which are involved in the regulation of numerous pathological processes such as inflammation, blood coagulation, the leukocyte-endothelial interaction, vasoconstriction, platelet aggregation and proteolysis [2-7]. Although risk factors for CVDs such as high

\footnotetext{
* Corresponding author.

** Corresponding author.

E-mail addresses: angelgil@cebas.csic.es (Á. Gil-Izquierdo), kmunoz@serviciosnutresa.com, kmunos@gmail.com (K. Muñoz-Durango).

${ }^{1}$ Present address: Grupo de investigación en Ciencias Farmacéuticas-ICIF-CES. Facultad de Ciencias y Biotecnología, Universidad CES, Calle 10A No. 22-04, Medellín, Colombia.

${ }^{2}$ Present address: Grupo de investigación NUTRAL-CES. Facultad de Ciencias de la Nutrición y los Alimentos, Universidad CES, Calle 10A No. 22-04, Medellín, Colombia.
} 


\section{Abbreviations}

AA Arachidonic acid

CA caffeic acid

CQA caffeoylquinic acid

CGA chlorogenic acid

CVDs cardiovascular diseases

DHCA dihydrocaffeic acid

DHFA dihydroferulic acid

diCQA dicaffeoylquinic acid

DiI 1, 1'-dioctadecyl-3,3,3',3'-tetramethylindocarbocyanine perchlorate

dihomo-IsoPs dihomo-isoprostanes

FA ferulic acid

hs-CRP high-sensitivity C-reactive protein

iFA isoferulic acid

IsoP isoprostane

KMO Kaiser-Meyer-Olkin
LDL low-density lipoprotein

LDH lactate dehydrogenase

LOX-1 lectin-like oxLDL receptor-1

oxLDL oxidized low-density lipoprotein

MFI mean fluorescence intensity

MS mass spectrometry

PBS phosphate-buffered saline

NeuroPs neuroprostanes

PAs phenolic acids

PMA phorbol 12-myristate-13-acetate

PG prostaglandin

EP prostaglandin E receptor

PUFAs polyunsaturated fatty acids

ROS reactive oxygen species

SPE solid phase extraction

UHPLC ultra-high performance liquid chromatography

CoA 4-coumaric acid.
LDL and low HDL levels, obesity, smoking, diabetes, hypertension, and elevated high-sensitivity C-reactive protein (hs-CRP), among others, may contribute to CVDs by different independent mechanisms, evidence shows that most of these factors increase lipid peroxidation. Therefore, two-to three-fold higher levels of IsoPs have been found in people with the risk factors mentioned above $[1,8,9]$.

Dyslipidemia triggers abnormal lipoprotein retention, endothelial cell activation, recruitment of circulating monocytes and LDL oxidation (oxLDL) into the intima of the vascular wall [10], leading to the transformation to foam cells that promote vascular inflammatory responses through innate receptors, such as the Toll-like receptors, scavenger receptors (SR-A and CD36) and lectin-like oxLDL receptor-1 (LOX-1) [11-13]. Evidence shows that the formation of IsoPs may occur in atherosclerotic lesions. A positive correlation has been revealed between coronary heart disease with IsoP levels, and it has been suggested that atherosclerotic tissue is a significant source of IsoPs found in circulation and urine [8]. Nevertheless, the contribution of oxylipin production by macrophage foam cells has been poorly explored. To date,

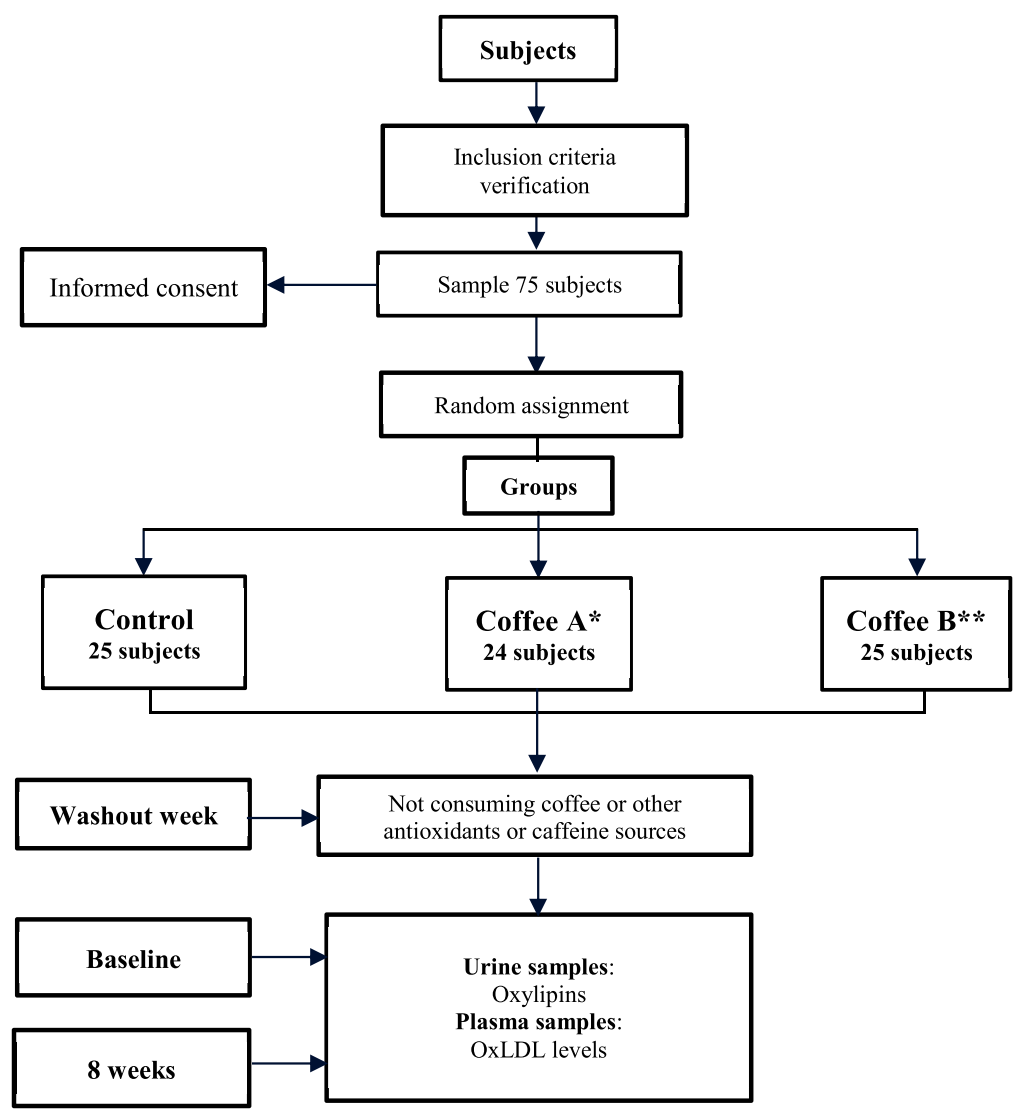

* Coffee A: intake $400 \mathrm{ml}$ coffee with high content of chlorogenic acids $(787 \mathrm{mg})$.

** Coffee B: intake $400 \mathrm{ml}$ coffee with medium content of chlorogenic acids $(407 \mathrm{mg}$ ).

Fig. 1. Study design. 
some reports have shown that oxLDL alters cell lipid metabolism, contributing to the progression of atheroma by stimulating arachidonic acid metabolism [13].

Epidemiological and clinical evidence on coffee consumption indicates that it may prevent CVDs and related risk factors [14-16]. In fact, some atherogenic events have been considered targets of the phenolic compounds present in foods $[17,18]$. After coffee uptake, a wide variety of compounds, such as phenolic (PAs), caffeoylquinic (CQAs) and dicaffeoylquinic (diCQAs) acids, are bioavailable [19,20], and some are anti-inflammatory, protect against LDL oxidation [21-23] and enhance cholesterol efflux from macrophages [24,25]. Nevertheless, information about the effects of coffee consumption on the oxylipin profile is limited and has only focused on IsoPs, specifically 15$\mathrm{F}_{2 \mathrm{t}}$-IsoP (8-iso- $\mathrm{PGF}_{2 \alpha}$ ), with contrasting results [26-29]. Because the reduction in oxylipins should indicate a direct reduction in lipid peroxidation in the vessel walls that drives atherogenesis, plasmatic or urinary oxylipins can be used as surrogate endpoints in intervention trials that evaluate the in vivo effects of bioactive compounds from food related to oxidation and inflammation in humans [30-35].

In previous studies, we described the oxylipin profiles of macrophages stimulated with oxLDL and determined the degree of inflammation and oxidative stress [36]. We also evaluated markers of coffee intake and the effects of its consumption on the plasma antioxidant capacity, lipid profile, and vascular function in healthy adults $[23,37]$. Since we found that coffee had no effects on circulating LDL or vascular function but that the antioxidant capacity of plasma increased after acute intake, it is of great relevance to determine the impact of coffee consumption on the oxylipin profile and oxLDL levels in vivo. In the present study, we evaluated 35 oxylipins and oxLDL after eight weeks of consumption of two types of coffees. Additionally, we investigated the in vitro activity of 12 coffee compounds among the PAs and CGAs against the cellular proatherogenic response in foam cells by using an oxLDL-macrophage interaction model on the production of 15 oxylipins [36]. The inhibition of oxLDL uptake and ROS production as well as proatherogenic receptor (CD36, SR-A and LOX-1) downregulation is also described. Remarkably, we report for the first time massive oxylipin regulation after coffee consumption and its bioavailable antioxidants by using in vivo and in vitro approaches, where oxLDL is a key inductor of the inflammatory and oxidative stress response.

\section{Materials and methods}

\subsection{Design of the study}

This randomized controlled parallel clinical trial, single-blind for the analysis, lasted eight weeks. The sample size was calculated based on differences in plasma antioxidant capacity: $22 \pm 12 \mu \mathrm{mol} \mathrm{Fe}{ }^{2+} \mathrm{L}^{-1}$ using FRAP after coffee consumption [38], and on changes in the levels of LDL-C: $17.1 \pm 18.8 \mathrm{mg} \mathrm{dL}^{-1}$. For a power of 0.8 and a significance level of $0.05,25$ subjects were needed per group (Fig. 1). After volunteers signed informed consent, they were randomly assigned by computer-generated sequences to three study groups, matched by age, gender and body mass index (BMI). The control group did not consume coffee, and 2 intervention groups drank $400 \mathrm{~mL} /$ day of one of 2 types of coffees for 8 weeks, which differed with respect to CGA concentration. Coffee A provided $787 \mathrm{mg}$ /day CGAs, and Coffee B provided $407 \mathrm{mg}$ / day CGAs. Both coffees were low in kahweol and cafestol, and the caffeine content was within the recommended range (Supplementary Table S1). Inclusion criteria: men or women between 20 and 60 years old; BMI between 18.8 and $30 \mathrm{~kg} / \mathrm{m}^{2}$; regular coffee drinker, at least $300 \mathrm{~mL} /$ day; nonsmoker; physical activity of less than $10 \mathrm{~h} /$ week; no history and/or diagnosis of chronic disease; not currently consuming medication (lipid-lowering, antioxidant dietary supplements, anticonvulsants, anti-inflammatory steroids, hypnotics, or caffeine); and a maximum alcohol consumption of $10 \mathrm{~g} /$ day for women and $15 \mathrm{~g}$ /day for men (beer: $300 \mathrm{~mL}, 4 \%$; distilled drinks: $35 \mathrm{~mL}, 37 \%$; and white wine: $90 \mathrm{~mL}, 12 \%$ alcohol degree). Pregnant or nursing women, highly competitive athletes and vegetarians were excluded. The clinical trial was approved by the CES University Ethics Committee (Act 47; project 142. May 16th, 2012) and registered on the International Clinical Trials Registry Platform, WHO primary registry (RPCEC00000168).

During the washout period (one week before of the beginning of the study) and during the eight weeks of the intervention, all participants avoided consuming beverages or foods with caffeine and naturally high in antioxidants (tea, dark chocolate, red wine, cocoa-derived products, herb infusions, berries, and soy). They also avoided any antioxidant supplements, and the consumption of caffeine-containing drugs was forbidden. The participants were allowed to consume water, juices, milk and beverages without caffeine. Except the mentioned restrictions, the volunteers continued their usual diets and lifestyles during the intervention. During the study, the coffee drink was prepared and provided in the workplace; the volunteers were trained to prepare the drink they needed to prepare on weekends, and the coffee maker, filters, cups and ground coffee were provided.

\subsection{Sample collection}

Venous blood samples were taken after a $12 \mathrm{~h}$ overnight fast. Plasma was obtained using EDTA as an anticoagulant by centrifugation at 1200 $\times g$ for $15 \mathrm{~min}$ at $4{ }^{\circ} \mathrm{C}$; urine samples were also collected and stored at $-80^{\circ} \mathrm{C}$ until analysis. At baseline and eight weeks after coffee consumption, the oxylipins were evaluated in the urine samples. Urine was used in order to avoid isobaric species generation or ion suppress effect [39]. The oxLDL levels were analyzed in the plasma samples. The plasma and urine measurements at eight weeks were performed in samples collected $21 \mathrm{~h}$ after the last coffee consumption.

\subsection{Chemicals and materials}

The LC-MS grade solvents were purchased from J.T. Baker (Phillipsburg, New Jersey, USA). Formic acid was obtained from Panreac (Castellar Del Vallés, Barcelona, SPA). The $\beta$-glucuronidase from Helix pomatia (type $\mathrm{H}-2$ ) was provided by Sigma-Aldrich (St. Louis, Missouri, USA). Chloromethyl-2', $7^{\prime}$-dichlorofluorescein diacetate (CM- $\mathrm{H}_{2}$ DCFDA) and $1,1^{\prime}$-dioctadecyl-3,3,3', $3^{\prime}$-tetramethylindocarbocyanine perchlorate (DiI) were obtained from Invitrogen Life Technologies (Carlsbad, California, USA). Solid phase extraction (SPE) cartridges (Strata X and X$\mathrm{AW}, 100 \mathrm{mg}, 3 \mathrm{~mL}^{-1}$ ) were purchased from Phenomenex (Torrance, California, USA).

Chlorogenic and phenolic acids: Ferulic (FA; 98.5\%; CAS number 1135-24-6), 4-caffeoylquinic (4-CQA; 99.8\%; CAS number 905-99-7), 5caffeoylquinic (5-CQA; 99.3\%; CAS number 906-33-2), 3,4-dicaffeoylquinic (3,4-diCQA; 98.9\%; CAS number 14534-61-3), 3,5-dicaffeoylquinic (3,5-diCQA; 99.2\%; CAS number 2450-53-5), and 4,5dicaffeoylquinic (4,5-diCQA, 98.2\%; CAS number 57378-72-0) acids were obtained from Biopurify Phytochemicals., Ltd. (Chengdu, Sichuan CN). The acids caffeic (CA; 98.5\%; CAS number 331-39-5), dihydrocaffeic (DHCA; 95\% CAS number 1078-61-1), isoferulic (iFA; $90 \%$ CAS number 537-73-5), 4-coumaric (CoA; 90\%; CAS number 7400-080 ) and 3-caffeoylquinic (3-CQA; 99\%; CAS number 327-97-9) were from Extrasynthese S.A. (Lyon, Auvernia-Ródano-Alpes, FR). Dihydroferulic acid (DHFA; 98.6\%; CAS number 1135-23-5) was purchased from TCI America, Ltd (Tokio, Kanto, JP). The compound stock solutions were prepared at a concentration of $20 \mathrm{mM}$ in DMSO and stored at $-20{ }^{\circ} \mathrm{C}$. In addition, a mixture of all compounds ( $1 \mathrm{mM}$ each) was prepared in PBS.

Oxylipins: Six isoprostanes (15- $\mathrm{F}_{2 \mathrm{t}}$-IsoP, 15-keto-15- $\mathrm{F}_{2 \mathrm{t}}$-IsoP, 9-epi$15-\mathrm{F}_{2 \mathrm{t}}$-IsoP, $15-$ keto-15- $_{2 \mathrm{t}}$-IsoP, $15-\mathrm{E}_{1 \mathrm{t}}$-IsoP and $15-\mathrm{F}_{1 \mathrm{t}}$-IsoP), fifteen prostaglandins (tetranor-PGEM (a tetranor-PGE-metabolite), tetranorPGAM (a tetranor-PGA-metabolite), 20-OH-PGE 2 , 15-keto $\mathrm{PGF}_{2 \alpha}$, tetranor PGFM (a tetranor-PGF-metabolite), 20-OH-PGF $2 \alpha, 19(\mathrm{R})-\mathrm{OH}$ $\mathrm{PGF}_{2 \alpha}, \quad \mathrm{PGD}_{2}, \quad 11 \beta-\mathrm{PGF}_{2 \alpha}, \quad 2,3$-dinor-11ß-PGF $2 \alpha$, PGDM (a PGD- 
metabolite), tetranor-PGDM (a tetranor-PGD-metabolite), tetranorPGJM (a tetranor-PGJ-metabolite), $\mathrm{PGE}_{1}$ and $\mathrm{PGF}_{1 \alpha}$ ) and one thromboxane (11-dehydrothromboxane $\mathrm{B}_{2}\left(\mathrm{TXB}_{2}\right)$ ) were from Cayman Chemical (Ann Arbor, Michigan, USA). Seven additional isoprostanes (2,3-dinor-15- $\mathrm{F}_{2 \mathrm{t}}$-IsoP, 2,3-dinor-15-epi-15- $\mathrm{F}_{2 \mathrm{t}}$-IsoP, 5- $\mathrm{F}_{2 \mathrm{t}}$-IsoP, 5-epi$\mathrm{F}_{2 \mathrm{t}}$-IsoP, 15-epi-15- $\mathrm{E}_{2 \mathrm{t}}-\mathrm{IsoP}, 8-\mathrm{F}_{3 \mathrm{t}}$-IsoP and 8-epi-8- $\mathrm{F}_{3 \mathrm{t}}$-IsoP) and nine NeuroPs/dihomo-IsoPs (4(RS)- $\mathrm{F}_{4 \mathrm{t}}$-NeuroP, 10-epi-10- $\mathrm{F}_{4 \mathrm{t}}$-NeuroP, $10-$

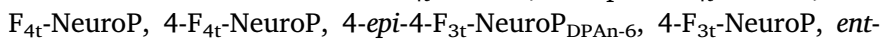
7(RS)-7- $\mathrm{F}_{2 \mathrm{t}}$-dihomo-IsoP, 17- $\mathrm{F}_{2 \mathrm{t}}$-dihomo-IsoP and 17-epi-17- $\mathrm{F}_{2 \mathrm{t}}$-dihomo-IsoP) were synthesized by Durand's team at the Institut des Biomolécules Max Mousseron (IBMM), (Montpellier, France) according to previously published procedures [40-45].

Coffee beverage preparation and chemical characterization: Coffee was prepared by the drip paper-filtered method, using $6 \mathrm{~g}$ of coffee per $100 \mathrm{~mL}$ of water. Chemical characterization is presented in Supplementary Table S1. The coffees used in this study were Colombian Arabica varieties (Coffea arabica); Coffee A and B were produce by the industry Colcafé S.A.S under light and dark roasting process, respectively. The ground coffee was stored until its preparation in laminate packaging with a nitrogen-modified atmosphere.

\subsection{Oxylipin determination}

Sample preparation: Urine samples were thawed at room temperature and centrifuged $(11,000 \times g, 5 \mathrm{~min})$. To assess the concentrations of oxylipins (IsoPs, $\mathrm{TXB}_{2}$, PGs, NeuroPs and Dihomo-IsoPs), all samples were hydrolyzed using $\sim 5000 \mathrm{UE} \mathrm{mL}^{-1} \beta$-glucuronidase, type $\mathrm{H} 2$ from Helix pomatia, and $0.1 \mathrm{M}$ acetate buffer ( $\mathrm{pH} 4.9$ ) for $2 \mathrm{~h}$ at $37^{\circ} \mathrm{C}$. Then, $500 \mu \mathrm{L}$ of methanol/200 mM HCl was added to the mix followed by centrifugation at $10,000 \times g$ for $5 \mathrm{~min}$ to precipitate the proteins. One milliliter of supernatant was mixed with $1250 \mu \mathrm{L}$ of methanol and $2 \mathrm{~mL}$ of Bis-Tris buffer with $0.02 \mathrm{M} \mathrm{HCl}(\mathrm{pH} 7.0)$ and subjected to SPE with a Strata X-AW cartridge. Target compounds were eluted with $1 \mathrm{~mL}$ of methanol and dried using a SpeedVac concentrator (Savant SPD121P; Thermo Scientific, MA, USA). The extracts were reconstituted in $200 \mu \mathrm{L}$ of solvent A/B $(90: 10, v / v)$ and filtered through a $0.45 \mu \mathrm{m}$ PVDF (polyvinyl difluoride) filter (Millipore, MA, USA) [31,46,47].

UHPLC-QqQ-MS/MS analyses: The separation of oxylipins in urine was performed using a UHPLC coupled with a 6460 QqQ-MS/MS (Agilent Technologies, Waldbronn, Germany), using the setup described by Medina et al. [46,47] with modifications. The chromatographic separation was performed on an Acquity UPLC BEH C18 column $(2.1 \times 150 \mathrm{~mm}, 1.7 \mu \mathrm{m}$; Waters; Milford, MA, USA $)$ for IsoPs, $\mathrm{TXB}_{2}$ and PGs and an Acquity UPLC BEH C18 column $(2.1 \times 50 \mathrm{~mm}$, $1.7 \mu \mathrm{m}$; Waters; Milford, MA, USA) for NeuroPs and Dihomo-IsoPs. The column temperature was $6^{\circ} \mathrm{C}$, and the sample volume injected was $20 \mu \mathrm{L}$. The mobile phases employed were solvent $\mathrm{A}\left(\mathrm{H}_{2} \mathrm{O}\right.$ /acetic acid; 99.99:0.01, $v / v)$ and $\mathrm{B}(\mathrm{MeOH} /$ acetic acid; 99.99:0.01, $v / v)$. The flow rate was $0.15 \mathrm{~mL} / \mathrm{min}$ using a linear gradient scheme (minutes; \%B): (0.00; 60), (7.00; 60), (7.01; 73), (10.00; 73), (10.01; 80), (18.00; 100), $(19.00 ; 100)$, and $(19.01 ; 60)$ for IsoPs, TXB $_{2}$ and PGs analysis $[32,46]$, and a flow rate of $0.2 \mathrm{~mL} / \mathrm{min}$ using a linear gradient scheme: (min; \% B): (0.0; 60.00), (7.00; 70.00), (7.01; 90.00), (10.00; 90.00), (10.01; 60.00) for NeuroPs and Dihomo-IsoPs determination [47]. The MS analysis was applied in MRM (multiple reaction monitoring) quantification mode using negative ESI. The operating conditions for the MS parameters were as follows: gas flow: $8 \mathrm{~L} / \mathrm{min}$, nebulizer: $30 \mathrm{psi}$, capillary voltage: $4000 \mathrm{~V}$, nozzle voltage: $2750 \mathrm{~V}$, gas temperature: $325^{\circ} \mathrm{C}$, sheath gas temperature: $350{ }^{\circ} \mathrm{C}$, and jet-stream gas flow: $12 \mathrm{~L} /$ $\mathrm{min}$. The MS fragmentor parameters (ion optics; capillary exit voltage) and collision energy of the new analytes were optimized for each compound to generate the most abundant product ions [32]. The MS parameters ranged from 50 to $160 \mathrm{~V}$, and the collision energy ranged from 0 to $24 \mathrm{~V}$. Data acquisition and processing were performed using MassHunter software version B.04.00 (Agilent Technologies). The quantification of oxylipins detected was performed using authentic markers calculated from the area ratio of the ion peak of each compound to that of the corresponding standard. Stock solutions of oxylipins were diluted with methanol-water $(1: 1, v / v)$ to obtain the appropriate working solutions at a concentration of $1000 \mathrm{nmol} \mathrm{L}^{-1}$. For the determination of the calibration curve, twelve successive dilutions were prepared. All solutions were stored at $-80^{\circ} \mathrm{C}$. The oxylipin concentrations were calculated from standard curves freshly prepared each day.

\subsection{Creatinine determination}

Urinary creatinine was measured by a commercial colorimetric kit assay (Alinity c, Creatinine (Enzymatic) Reagent Kit, Abbott Park, Illinois, USA).

\subsection{OxLDL levels}

The concentration of oxLDL in plasma was determined by ELISA (Mercodia kit; Uppsala, Sweden) at $450 \mathrm{~nm}$ using a Synergy HT MultiMode Microplate Reader (BioTek Instruments Inc., Winoski, USA). The results are reported as $\mathrm{UL}^{-1}$.

\subsection{LDL isolation}

LDL was purified from each plasma sample according to methods previously described by a discontinuous density gradient using a Beckman XL-100 ultracentrifuge (Brea, California, USA) [23,36]. Briefly, the LDL fraction was collected and desalted by ultrafiltration with ultra-centrifugal filters $0.5 \mathrm{~mL}$, Ultracel $3 \mathrm{~K}$ (Amicon; Tullagreen, Cork, IRL) against five-fold PBS at $16,000 \times g$ for $10 \mathrm{~min}$ at $4^{\circ} \mathrm{C}$. LDL was diluted in PBS, filtered $\left(0.22 \mu \mathrm{m}\right.$, sterile) and stored at $4^{\circ} \mathrm{C}$ until use. The protein concentration was measured by a commercial kit (Pierce BCA Protein Assay Kit; Rockford, Illinois, USA).

\subsection{Macrophage culture and treatments}

The in vitro effect of all CGAs and PAs on macrophage proatherogenic responses (oxLDL receptor expression, oxLDL uptake, ROS production, and oxylipin profile) was assessed in THP-1 monocyte-derived macrophages (ATCC TIB-202 ${ }^{\mathrm{TM}}$ ); their culture and differentiation conditions are described in Lara-Guzmán O.J. et al. [36]. Cells were seeded and treated according to their respective experimental analysis: 96-well plates with $1.5 \times 10^{5}$ cells/well for cell viability; 48-well plates with $3 \times 10^{5}$ cells/well for flow cytometry analysis; and 24-well plates with $1 \times 10^{6}$ cells/well for UHPLC-QqQ-MS/MS assays. Prior to oxLDL-induced macrophage activation, the macrophages were pretreated with $1 \mu \mathrm{M}$ of each compound. The final concentration in the cell cultures was based on the previous bioavailability $[19,20]$. The negative control was the vehicle in an equivalent volume $(<0.05 \%$ DMSO). The treatment time depended on the assay as follows: $48 \mathrm{~h}$ for cell viability; $12 \mathrm{~h}$ for oxLDL receptors and oxLDL uptake experiments; and $1 \mathrm{~h}$ for ROS and oxylipin production. The length of exposure to $25 \mu \mathrm{g} \mathrm{mL}^{-1}$ oxLDL depended on the assay as follows: $36 \mathrm{~h}$ for experiments of cell viability and oxLDL receptors; $6 \mathrm{~h}$ for oxLDL uptake; $1 \mathrm{~h}$ for ROS production; and $12 \mathrm{~h}$ for lipidomic analysis targeted to oxylipins. The positive control was the oxLDL treatments and the vehicle $(<0.05 \%$ DMSO). The oxLDL used in this experiment was obtained after LDL was oxidized for $6 \mathrm{~h}$ with $5 \mu \mathrm{M} \mathrm{CuSO} \mathrm{C}_{4}$ at $37^{\circ} \mathrm{C}$. The complete procedure was fully detailed previously [36].

\subsection{Phenotypic and functional analysis of macrophage foam cells}

ROS production: Cells were incubated with $2 \mu \mathrm{M}$ fluorescent ROSsensitive probe CM- $\mathrm{H}_{2}$ DCFDA from Invitrogen ${ }^{\mathrm{TM}}$ (Carlsbad, California, USA). The oxLDL at $37^{\circ} \mathrm{C}$ was washed twice, resuspended in PBS, and analyzed by flow cytometry. 
OxLDL uptake: LDL (1 $\mathrm{mg} \mathrm{mL}^{-1}$ ) was labeled with the DiI [36]; LDL was incubated with $0.1 \mu \mathrm{g} \mathrm{mL}{ }^{-1}$ DiI for $12 \mathrm{~h}$ at $37^{\circ} \mathrm{C}$ under a nitrogen atmosphere in the dark. The DiI-LDL complex $\left(0.5 \mathrm{mg} \mathrm{mL}^{-1}\right)$ was then oxidized as mentioned before. Unbound dye in the DiI-oxLDL particles and copper ions were removed by ultrafiltration with ultra-centrifugal filters, as mentioned for the LDL isolation assay. After treatment, the cells were washed three times with PBS and harvested with trypsin working solution $(0.25 \%$ trypsin, $0.02 \%$ EDTA). Then, macrophages were centrifuged at $300 \times g$ for $5 \mathrm{~min}$, washed once with RPMI 1640/ $10 \%$ FBS at $37^{\circ} \mathrm{C}$ and twice with PBS at $300 \times g$ for 5 min at $4{ }^{\circ} \mathrm{C}$. The uptake of DiI-oxLDL by macrophages was analyzed by flow cytometry.

OxLDL receptors: The surface expression of CD36, SR-A and LOX-1 was analyzed by flow cytometry. After treatments, the macrophage cultures were washed with PBS and harvested from the wells with cold PBS supplemented with EDTA $(0.2 \%)$ and a cell scraper. Nonspecific binding of antibodies was blocked by incubating cells in 10\% FBS-PBS. Cells were incubated with purified human monoclonal antibodies (R\&D Systems; Minneapolis, Minnesota, USA) against CD36/SR-B3 fluorescein (clone 255606; Cat\#FAB19551F, RRID:AB_1026194), LOX-1/ OLR1 PerCP (clone 331212; Cat\#FAB1798P, RRID: AB_10718092), SRA/MSR1 phycoerythrin (clone 361615; Cat\#FAB2708P, RRID:AB_2044631) or their isotypes controls, rat IgG2B fluorescein (clone 141945; Cat\# IC013F, RRID:AB_357258), mouse IgG2B PerCP (clone 133303; Cat\#IC0041C, RRID:AB_1207938) and mouse IgG2B phycoerythrin (clone 133303; Cat\#IC0041P, RRID:AB_357249) using $1 \mu \mathrm{L}$ per 100,000 cells and submitted to flow cytometry.

Cell viability: Lactate dehydrogenase (LDH) was quantified in the supernatants collected after the treatment period with a commercial viability test (LDH assay kit; Promega, Madison, USA) at $340 \mathrm{~nm}$ using a synergy HT multimode microplate reader (BioTek Instruments Inc; Winooski, Vermont, USA). The samples and controls were evaluated in triplicate, and the results are expressed as the percent of cell viability.

Flow cytometry analysis: DiI-oxLDL uptake, oxLDL receptors and ROS production (DCF) in macrophages were analyzed using a FACS Canto II flow cytometer (Beckton Dickinson; San José, California, USA) for all acquisitions (at least 10,000 events). Analysis was performed with FlowJo software. The data were calculated by subtracting the cell autofluorescence and/or isotype control fluorescence from the fluorescence of the treated samples. The results are expressed as the mean fluorescence intensity (MFI).

Oxylipin extraction and analysis in supernatants: the supernatants from foam cell assays were collected after the treatments with CGAs and PAs, supplemented with BHT to avoid further oxidation $(0.05 \% \mathrm{v} /$ $v$ ) and kept at $-80{ }^{\circ} \mathrm{C}$ until oxylipin extraction. To precipitate the proteins, $500 \mu \mathrm{L}$ of each supernatant sample was mixed with $500 \mu \mathrm{L}$ of zinc sulfate $(0.1 \mathrm{M})$ and, centrifuged at $10,000 \times \mathrm{g}$ for $5 \mathrm{~min}$. To assess the concentrations of oxylipins, the samples were first hydrolyzed and then extracted according to the procedure previously described $[36,46]$. Briefly, all samples were hydrolyzed using $\sim 5000 \mathrm{UE} \mathrm{mL}^{-1}$ of $\beta$-glucuronidase type $\mathrm{H} 2$ from Helix pomatia in $0.1 \mathrm{M}$ acetate buffer $(\mathrm{pH}$ 4.9) for $2 \mathrm{~h}$ at $37^{\circ} \mathrm{C}$. Then, methanol $/ 200 \mathrm{mM} \mathrm{HCl}(500 \mu \mathrm{L})$ was added to the mix and centrifuged at $10,000 \times \mathrm{g}$ for $5 \mathrm{~min}$ to precipitate the proteins. Finally, the collected supernatant $(1 \mathrm{~mL})$ was mixed with $1250 \mu \mathrm{L}$ of methanol and $2 \mathrm{~mL}$ of Bis-Tris buffer with $0.02 \mathrm{M} \mathrm{HCl}(\mathrm{pH}$ 7.0) and subjected to SPE using a Strata X-AW cartridge (100 mg, $3 \mathrm{~mL}^{-1}$ ). Target compounds were eluted with $1 \mathrm{~mL}$ of methanol and dried using a SpeedVac concentrator (Savant SPD121P, Thermo Scientific, MA, USA) before injection onto the UHPLC-QqQ-MS/MS. The

Table 1

Isoprostanoids and oxLDL, markers of oxidative stress in vivo, in healthy adults at baseline and 8 weeks after intervention. ${ }^{\text {a }}$

\begin{tabular}{|c|c|c|c|c|c|c|}
\hline & \multirow{2}{*}{$\begin{array}{l}\text { Control } \\
\mathrm{n}=25\end{array}$} & \multirow{2}{*}{$\begin{array}{l}\text { Coffee A } \\
n=24\end{array}$} & \multirow{2}{*}{$\begin{array}{l}\text { Coffee B } \\
\mathrm{n}=25\end{array}$} & \multirow[t]{2}{*}{ Treatment } & \multirow{2}{*}{$\begin{array}{l}p \\
\text { Time }\end{array}$} & \multirow[t]{2}{*}{ Interaction } \\
\hline & & & & & & \\
\hline \multicolumn{7}{|c|}{$15-F_{2 t}$-IsoP } \\
\hline Baseline & $0.31 \pm 0.21$ & $0.40 \pm 0.35$ & $0.35 \pm 0.25$ & 0.982 & $<0.001$ & 0.497 \\
\hline $8 w k$ & $0.60 \pm 0.48 * *$ & $0.56 \pm 0.51$ & $0.49 \pm 0.33 *$ & & & \\
\hline \multicolumn{7}{|c|}{ 15-E $1 \mathrm{t}$-IsoP } \\
\hline Baseline & $1.06 \pm 0.67$ & $1.62 \pm 1.12$ & $1.21 \pm 0.79$ & 0.349 & 0.004 & 0.041 \\
\hline $8 w k$ & $0.97 \pm 0.57$ & $0.92 \pm 0.52 * * *$ & $1.12 \pm 0.90$ & & & \\
\hline \multicolumn{7}{|c|}{ 15-keto-15E $\mathrm{E}_{2 \mathrm{t}}$-IsoP } \\
\hline Baseline & $1.00 \pm 0.56$ & $1.26 \pm 0.65$ & $1.04 \pm 0.58$ & 0.557 & $<0.001$ & 0.319 \\
\hline $8 w k$ & $0.72 \pm 0.44 *$ & $0.71 \pm 0.41 * * *$ & $0.76 \pm 0.40$ & & & \\
\hline \multicolumn{7}{|c|}{ 2,3-dinor-15-epi-15- $\mathrm{F}_{2 \mathrm{t}}$-IsoP } \\
\hline Baseline & $5.12 \pm 4.80$ & $6.07 \pm 4.16$ & $5.70 \pm 5.27$ & 0.536 & 0.590 & 0.866 \\
\hline $8 w k$ & $2.77 \pm 1.44$ & $3.45 \pm 2.34$ & $3.65 \pm 2.89$ & & & \\
\hline \multicolumn{7}{|c|}{ 2,3-dinor-15- $\mathrm{F}_{2 \mathrm{t}}$-IsoP } \\
\hline Baseline & $3.02 \pm 2.69$ & $3.24 \pm 2.01$ & $2.95 \pm 1.84$ & 0.759 & 0.002 & 0.903 \\
\hline $8 w k$ & $2.22 \pm 1.59$ & $2.21 \pm 1.34 *$ & $2.38 \pm 1.73$ & & & \\
\hline \multicolumn{7}{|l|}{$5-\mathrm{F}_{2 \mathrm{t}}-\mathrm{IsoP}$} \\
\hline Baseline & $7.48 \pm 3.98$ & $12.06 \pm 8.82$ & $9.50 \pm 5.78$ & 0.482 & 0.005 & 0.060 \\
\hline $8 w k$ & $7.82 \pm 4.93$ & $6.86 \pm 4.62 * *$ & $8.99 \pm 9.39$ & & & \\
\hline \multicolumn{7}{|c|}{ 5-epi-5-F $\mathrm{F}_{2 \mathrm{t}}$-IsoP } \\
\hline Baseline & $4.26 \pm 2.69$ & $6.65 \pm 4.77$ & $5.26 \pm 3.40$ & 0.205 & 0.007 & 0.244 \\
\hline $8 w k$ & $3.90 \pm 2.97$ & $4.26 \pm 3.22 * *$ & $5.02 \pm 5.86$ & & & \\
\hline \multicolumn{7}{|c|}{ 17-epi-17- $\mathrm{F}_{2 \mathrm{t}}$-dihomo-IsoP } \\
\hline Baseline & $3.79 \pm 1.92$ & $4.63 \pm 3.12$ & $4.38 \pm 2.22$ & 0.578 & 0.648 & 0.044 \\
\hline $8 w k$ & $4.27 \pm 2.34$ & $3.44 \pm 1.72 *$ & $4.54 \pm 2.50$ & & & \\
\hline \multicolumn{7}{|c|}{ 17-F Ft -dihomo-IsoP } \\
\hline Baseline & $4.19 \pm 2.22$ & $5.27 \pm 3.55$ & $4.96 \pm 2.69$ & 0.643 & 0.640 & 0.041 \\
\hline $8 w k$ & $4.72 \pm 2.67$ & $3.95 \pm 2.04 *$ & $5.05 \pm 2.86$ & & & \\
\hline \multicolumn{7}{|c|}{ ent-7 (RS)-7- $\mathrm{F}_{2 \mathrm{t}}$-dihomo-IsoP } \\
\hline Baseline & $4.49 \pm 2.64$ & $5.70 \pm 4.26$ & $5.20 \pm 2.99$ & 0.589 & 0.552 & 0.065 \\
\hline $8 w k$ & $4.91 \pm 3.22$ & $3.96 \pm 2.06 *$ & $5.38 \pm 3.12$ & & & \\
\hline \multicolumn{7}{|l|}{ OxLDL } \\
\hline Baseline & $67.72 \pm 20.30$ & $74.81 \pm 22.71$ & $67.89 \pm 23.37$ & 0.446 & 0.031 & 0.828 \\
\hline $8 w k$ & $64.92 \pm 18.33$ & $69.34 \pm 22.16$ & $63.73 \pm 18.68$ & & & \\
\hline
\end{tabular}

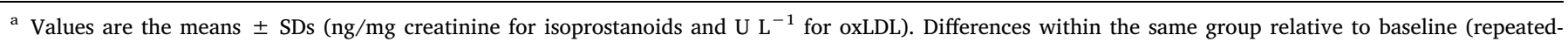
measures ANOVA: $* P<0.05 ; * * P<0.01 ; * * * P<0.001$. Adjusted for multiple comparisons: Bonferroni). IsoP: isoprostane. 
sample volume injected was $20 \mu \mathrm{L}$. This method evaluates free oxylipins after phospholipase action but not those oxylipins linked to phospholipids [48]. The separation of oxylipins was performed using a UHPLC coupled with a 6460 QqQ-MS/MS, with setup and protocols described above. The quantification of oxylipins was calculated from the area ratio of the ion peak of each compound to that of the corresponding standard. Data acquisition and processing were performed using MassHunter software version B.08.00 (Agilent Technologies).

\subsection{Statistical analysis}

Data are reported as the means \pm SD. The normality of the continuous variables in each group was evaluated with the Shapiro-Wilks test. To evaluate the effect of the type of coffee consumed, a repeated measures ANOVA that took into account 2 time points (baseline and 8 weeks) and the 3 treatment groups (control, Coffee A and Coffee B) was performed. When an interaction was significant, Tukey's post hoc tests were applied. Significance was defined as $P<0.05$, and 2-tailed tests were used. This statistical analysis was performed by using SPSS version 22 (IBM). To evaluate the effect of the treatments on ROS production, DiI-oxLDL uptake, oxLDL receptor expression and oxylipin production, one-way analysis of variance (ANOVA) was used. $P$ values $\leq 0.05$ were considered statistically significant. When differences were observed, Dunnett's and Bonferroni's multiple comparison tests were used. ANOVA was performed using Graph Pad Prism version 6.00 for Windows (GraphPad Software, Inc., San Diego, California, USA). The linear Pearson correlation was computed for each pair of oxylipins for the 900 observations in foam cells after treatment (except for the controls and the mixed treatment) and was visualized as a correlation matrix [49]. The Kaiser-Meyer-Olkin criterion was calculated for the data matrix using the REdaS package with the KMO function. Oxylipin analysis was performed by using Factoextra and FactoMineR R software to extract and visualize the output of exploratory multivariate data analyses [50,51]. R-statistical open source software (Rx64 version 3.5.0) was used. $\mathrm{R}$ refers to a language and environment for statistical computing ( $\mathrm{R}$ Foundation for Statistical Computing, Vienna, Austria; URL http://www.R-project.org/). The employed code and the database for statistical analyses of oxylipins in the foam cell model are available at Github (https://github.com/ojlara-vidarium/Oxylipins_Coffee_ Antioxidant).

\section{Results}

\subsection{Clinical trial}

Seventy-four volunteers completed the study, and one individual (Coffee A group) had alterations in the baseline lipid profile and required medication. The volunteers' mean age at the time of baseline was $38.0 \pm 9$ years, their BMI was $24.1 \pm 2.6 \mathrm{~kg} / \mathrm{m}^{2}$, and 37 were men and 37 were women. The characteristics of the volunteers in each group at baseline are described in Supplementary Table S2 and the chemical characterization of the two coffees used is described in Supplementary Table S1. In the control group at baseline and eight weeks after the intervention, no caffeine was detected in the plasma samples.

\subsection{Biomarkers of lipid peroxidation and inflammation after coffee consumption}

The effect of coffee consumption on lipid peroxidation markers is summarized in Table 1. Data on oxylipins are reported in $\mathrm{ng} / \mathrm{mg}$ creatinine. A significant time $\times$ treatment interaction was found for 15$\mathrm{E}_{1 \mathrm{t}}$-IsoP, 17-epi-17- $\mathrm{F}_{2 \mathrm{t}}$-dihomo-IsoP and 17- $\mathrm{F}_{2 \mathrm{t}}$-dihomo-IsoP $(P<0.05)$. A significant effect of time within the groups was observed $(P<0.05)$, especially in Group A, in which an important reduction was detected. Compared to the baseline, five IsoPs had a significant decrease in the Coffee A group $\left(\Delta 15-\mathrm{E}_{1 \mathrm{t}}\right.$-IsoP: $0.75 \pm 1.04 ;-46.6 \%$; $\Delta$ 15-keto-15-E $2 \mathrm{t}$-IsoP: $0.56 \pm 0.65 ;-44.6 \% ; \Delta 2,3-$ dinor- $15-\mathrm{F}_{2 \mathrm{t}}$-IsoP: $1.05 \pm 2.48 ;-32.3 \% ; \Delta 5-\mathrm{F}_{2 \mathrm{t}}$-IsoP: $5.49 \pm 7.82 ;-45.5 \%$; and $\Delta 5$ epi-5- $\mathrm{F}_{2 \mathrm{t}}$-IsoP: $\left.2.51 \pm 4.06 ;-37.8 \%\right)$. In contrast to the above, after eight weeks of Coffee $\mathrm{B}$ consumption, $15-\mathrm{F}_{2 \mathrm{t}}$-IsoP showed a significant increase of $40.0 \%$; nevertheless, its increment was observed in all groups, with a greater extent in the control: $\Delta 0.29 \pm 0.51,93.5 \%$. Coffee $\mathrm{A}$ also showed a reduction in $\mathrm{F}_{2}$-dihomo-IsoPs. Compared with the baseline, a significant decrease in 17-epi-17- $\mathrm{F}_{2 \mathrm{t}}$-dihomo-IsoP $(-1.19 \pm 2.38 ; \quad-25.6 \%), \quad 17-\mathrm{F}_{2 \mathrm{t}}$-dihomo-IsoP $\quad(-1.33 \pm 2.74$; $-25.1 \%)$ and ent-7(RS)-7- $\mathrm{F}_{2 \mathrm{t}}$-dihomo-IsoP $(-1.74 \pm 3.15 ;-30.5 \%)$ was observed. In contrast, in the control group, the dihomo-IsoPs increased, although not significantly, compared to the baseline (Table 1). After the intervention, the overall reduction of lipid peroxidation markers in the Coffee A group was approximately $35.4 \%$, while the Coffee B and control groups had a slight reduction of $7.8 \%$ and $5.2 \%$, respectively. Regarding the oxLDL levels, there were no significant differences in the plasmatic concentrations between the groups

Table 2

Prostaglandins and their metabolites, markers of inflammation in healthy adults, at baseline and 8 weeks after intervention. ${ }^{\text {a }}$

\begin{tabular}{|c|c|c|c|c|c|c|}
\hline & \multirow{2}{*}{$\begin{array}{l}\text { Control } \\
\mathrm{n}=25\end{array}$} & \multirow{2}{*}{$\begin{array}{l}\text { Coffee A } \\
\mathrm{n}=24\end{array}$} & \multirow{2}{*}{$\begin{array}{l}\text { Coffee B } \\
\mathrm{n}=25\end{array}$} & \multirow[t]{2}{*}{ Treatment } & \multirow{2}{*}{$\frac{p}{\text { Time }}$} & \multirow[t]{2}{*}{ Interaction } \\
\hline & & & & & & \\
\hline \multicolumn{7}{|c|}{$11 \beta-P_{G F} \alpha \alpha$} \\
\hline Baseline & $0.04 \pm 0.03$ & $0.06 \pm 0.05$ & $0.05 \pm 0.06$ & 0.685 & 0.006 & 0.383 \\
\hline 8 wk & $0.07 \pm 0.06 * *$ & $0.08 \pm 0.07$ & $0.06 \pm 0.04$ & & & \\
\hline \multicolumn{7}{|l|}{$\mathrm{PGE}_{1}$} \\
\hline Baseline & $0.31 \pm 0.19$ & $0.50 \pm 0.36$ & $0.40 \pm 0.26$ & 0.108 & 0.035 & 0.256 \\
\hline $8 w k$ & $0.30 \pm 0.23$ & $0.34 \pm 0.25 *$ & $0.37 \pm 0.31$ & & & \\
\hline \multicolumn{7}{|c|}{ Tetranor PGAM } \\
\hline Baseline & $1.38 \pm 1.62$ & $1.69 \pm 1.43$ & $1.76 \pm 1.65$ & 0.366 & $<0.001$ & 0.002 \\
\hline $8 w k$ & $1.28 \pm 1.35^{\mathrm{a}}$ & $0.50 \pm 0.36^{\mathrm{b}} * * *$ & $1.00 \pm 1.18^{\mathrm{a}} * * *$ & & & \\
\hline \multicolumn{7}{|c|}{ Tetranor PGDM } \\
\hline Baseline & $3.68 \pm 2.15^{\mathrm{a}}$ & $5.81 \pm 3.96^{\mathrm{a}, \mathrm{c}}$ & $6.91 \pm 4.68^{\mathrm{b}, \mathrm{c}}$ & 0.113 & 0.145 & 0.001 \\
\hline $8 w k$ & $6.04 \pm 4.20 *$ & $2.95 \pm 1.67 *$ & $5.08 \pm 4.30 *$ & & & \\
\hline \multicolumn{7}{|l|}{ PGDM } \\
\hline Baseline & $24.4 \pm 18.7$ & $31.5 \pm 22.5$ & $30.3 \pm 20.9$ & 0.220 & $<0.001$ & $<0.001$ \\
\hline $8 w k$ & $22.6 \pm 11.9^{a}$ & $11.9 \pm 7.5^{\mathrm{b}} * * *$ & $23.9 \pm 19.3^{\mathrm{a}}$ & & & \\
\hline
\end{tabular}

${ }^{\text {a }}$ Values are the means \pm SDs ng/mg creatinine. Labeled means in a row without a common letter differ significantly (repeated-measures ANOVA; $P<0.05$ ).

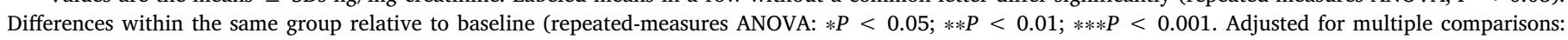
Bonferroni). PG, prostaglandin. 
(Table 1).

The urinary concentrations of PGs and their metabolites are summarized in Table 2. A significant time $\times$ treatment interaction was found for tetranor PGAM, tetranor PGDM and PGDM. A significant effect of time within the groups was also observed $(P<0.05)$, especially in Group A, in which an important reduction in $\mathrm{PGE}_{1}$, tetranor-PGAM, PGDM and tetranor-PGDM was detected. Similar to the isoprostanoids, the concentration of inflammatory markers remained unchanged in the control group eight weeks after intervention, except for $11 \beta-\mathrm{PGF}_{2 \alpha}$ and tetranor PGDM, which increased significantly by $75.0 \%$ and $64.1 \%$, respectively $(P<0.05)$. Compared to the control, the markers of inflammation that significantly decreased in the Coffee A group were tetranor-PGAM $(-1.20 \pm 1.33)$ and PGDM $(-22.99 \pm 22.96)$. In contrast, when Coffee B was compared to the control, only one inflammatory marker showed a significant reduction (tetranor-PGDM; $-1.82 \pm 7.00$ ).

The overall reduction in PGs and their metabolites in the Coffee A and B groups were approximately $60.1 \%$ and $22.9 \%$, respectively. No significant change was observed in the control group; nevertheless, it increased globally by $1.6 \%$.

\subsection{Foam cell model}

3.3.1. Effects of phenolic compounds on atherogenic markers in oxLDLstimulated macrophages

Neither oxLDL nor the treatments or their combination induced toxicity in macrophages after $48 \mathrm{~h}$ (Fig. 2A). The efficiency of DiI-oxLDL uptake by macrophages was confirmed using flow cytometry (Fig. 2B). Compared to the positive control $(\mathrm{C}+)$, the major reduction in the uptake of DiI-oxLDL was observed for 4-CQA $(P<0.001)$, followed by 3-CQA, DHFA and CoA $(P<0.01)$. Although significant, the diCQAs and 5-CQA exhibited less activity than the previous compounds $(P<0.05)$. In contrast, CA, DHCA, FA and iFA did not show any effect on oxLDL uptake $(P>0.05)$. For CD36, SR-A and LOX-1, which are responsible for approximately $90 \%$ of oxLDL uptake by macrophages [11,12,52], a significant reduction was observed for DHFA and diCQA treatments (Fig. 2D). 4,5-diCQA and DHFA significantly reduced the expression of CD36, SR-A and LOX-1 $(P<0.001)$, while 3,4-diCQA and CA significantly reduced LOX-1 $(P<0.01)$ and 3,5-diCQA and CoA inhibited CD36 $(P<0.05)$. Additionally, DHCA significantly reduced CD36 and LOX-1 $(P<0.05)$. The mix of all compounds was a potent inhibitor of oxLDL uptake $(P<0.001)$ and oxLDL receptors $(P<0.001)$.

Macrophage oxLDL triggers ROS production, contributing to atherosclerosis progression and aggravation [53,54]. As expected, oxLDL rapidly induced ROS production after $1 \mathrm{~h}$ (Fig. 2C). Notwithstanding, compared to $\mathrm{C}+$, when macrophages were pretreated with phenolic compounds and subsequently exposed to oxLDL, a significant reduction in ROS production was observed for 4,5-diCQA $(P<0.001)$, DHCA $(P<0.01)$, CoA $(P<0.05)$ and the mix $(P<0.05)$. As a global result, the mix was the most active treatment.
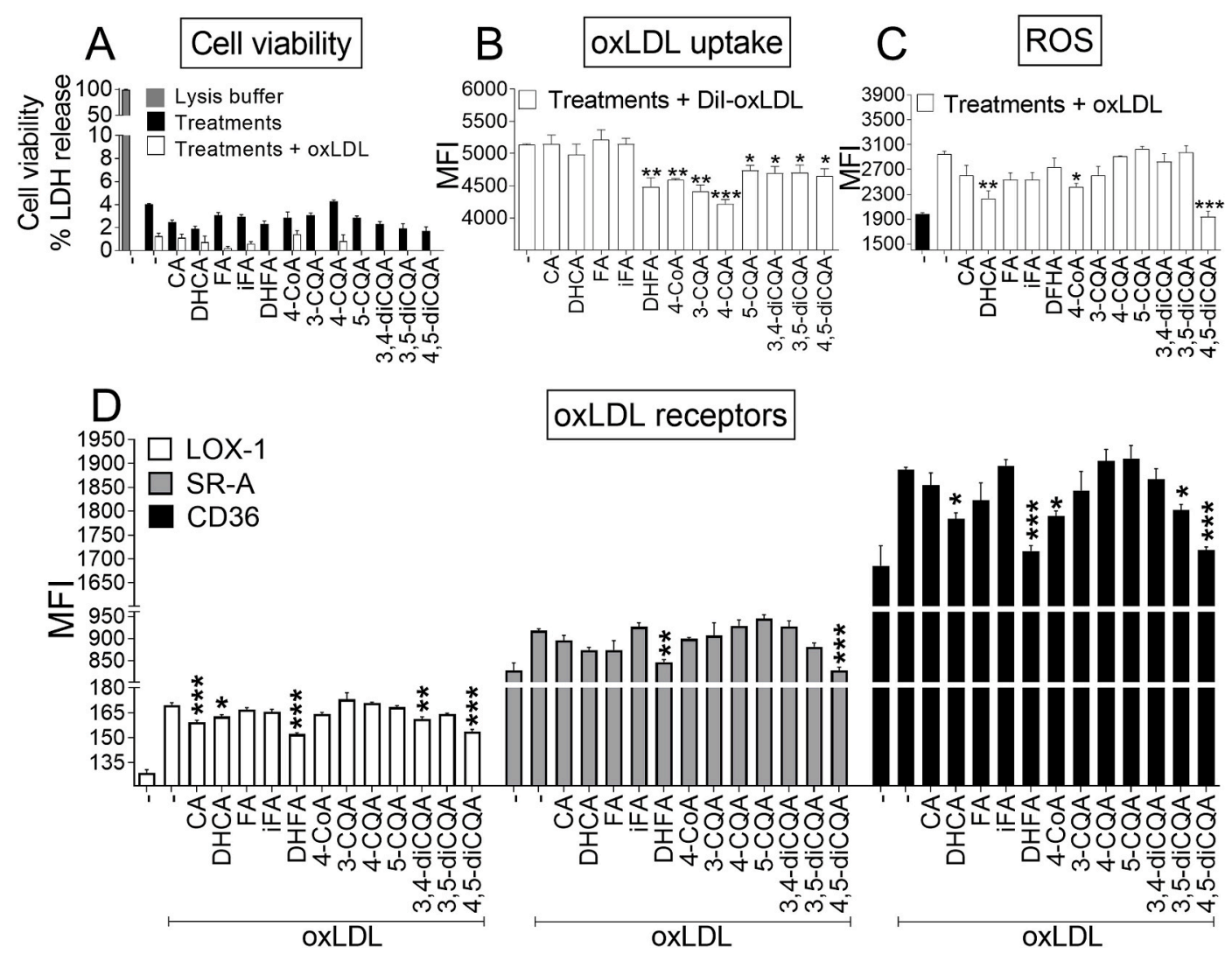

Fig. 2. Chlorogenic acid metabolites inhibit key events implicated in foam cell formation. A) Cell viability and LDH were measured and expressed as a percent of cell viability. B) Intracellular ROS production was monitored with a ROS-sensitive fluorescent dye. C) DiI-oxLDL uptake and D) oxLDL receptor expression were determined by flow cytometry. The concentration of ROS production, DiI-oxLDL uptake and receptor expression were expressed as the mean fluorescence intensity (MFI). Macrophages under basal conditions served as the negative control (C-) and macrophages stimulated with oxLDL or DiI-oxLDL correspond to the positive control $(\mathrm{C}+$ ). The compounds evaluated were caffeic (CA), dihydrocaffeic (DHCA), ferulic (FA), isoferulic (iFA), dihydroferulic (DHFA), 4-coumaric (CoA) acids, caffeoylquinic acids (3-CQA, 4-CQA and 5-CQA), dicaffeoylquinic acids (3,4-diCQA, 3,5-diCQA and 4,5-diCQA), and a mixture (mix) of all of them. Error bars represent the SD. One-way ANOVA: bars labeled with $*$ differ significantly compared with the positive control (Dunnett's multiple comparison test, $* P<0.05$, $* * P<0.01$ and $* * * P<0.001)$. 
3.3.2. Effects of phenolic compounds on oxylipins in oxLDL-stimulated macrophages

The concentrations of oxylipins in macrophages pretreated with CGAs and PAs exposed to oxLDL are summarized in Supplementary Table S3. Fig. 3 and Supplementary Table S4 show a high, inverse or no correlation among the oxylipins. We found a high degree of correlation ( $r \approx 0.6-0.9$ ) for the regulation of all IsoPs, which occurs independently of several inflammatory PGs (tetranor-PGDM and tetranorPGAM), or even an inverse correlation ( $\mathrm{r} \approx-0.3$ to -0.6 for tetranorPGEM and PGDM). Only two inflammatory PGs (15-keto-PGF $2 \alpha$ and $\left.11 \beta-\mathrm{PGF}_{2 \alpha}\right)$ [55-57] showed high correlations with IsoPs $(\mathrm{r} \approx 0.5-0.9)$. Interestingly, the regulation of anti-inflammatory $\mathrm{PGE}_{1}$ and IsoPs tended to correlate $(\mathrm{r} \approx 0.4-0.8)$, but $\mathrm{PGE}_{1}$ had a negative or null correlation with most of the inflammatory PGs. On the other hand, most of the inflammatory PGs (tetranor-PGDM, tetranor-PGAM, tetranorPGEM, and PGDM) had a high correlation ( $\mathrm{r} \approx 0.4-0.9)$. In summary, this analysis of correlations allowed us to propose that $i$ ) there is a regulatory pattern related to the phenolic compounds on oxylipin generation; ii) the negative correlation among isoprostanoids and inflammatory PGs implies that the biological activities of the compounds have different mechanisms of action; and iii) the lack of correspondence of inflammatory and anti-inflammatory $\mathrm{PGE}_{1}$, but the correspondence among $\mathrm{PGE}_{1}$ and IsoPs suggests that oxidative stress regulation is implicated in the activation of anti-inflammatory pathways.

In the PCA, the first and second PCs accounted for 54.4 and $22.5 \%$ of the variance, respectively (Fig. 4). IsoPs had the highest correlation and quality of representation for PC1, while PGs (inflammatory) had the highest correlation and quality of representation for PC2 (Fig. 4A; Supplementary Table S5). The projection of the treatments of these components (Fig. 4B) confirms that the active compounds regulate oxylipins. The PCA revealed four clusters, defined by convex ellipses and labeled as the following:
Induction cluster: Positive control $(\mathrm{C}+)$ and compounds with poor activity on this model (i.e., caffeic acid; CA); in these clusters, we found the highest concentration of oxylipins.

Anti-inflammatory cluster: This cluster includes the treatments with CoA, DHCA, 3,5-diCQA and 4,5-diCQA, which decreased the concentration of inflammatory markers (tetranor-PGEM, PGDM, tetranorPGAM, PGDM and 15-keto $\mathrm{PGF}_{2 \alpha}$ ). However, the inflammatory marker $11 \beta-\mathrm{PGF}_{2 \alpha}$ is discriminant for this cluster, with no effect of the compounds decreasing it, which is a similar behavior observed for the antiinflammatory $\mathrm{PGE}_{1}$ and isoprostanoids.

Antioxidant cluster: This cluster corresponds exclusively to the effect of CQAs, which notably decreased all IsoPs. Additionally, some inflammatory markers (tetranor-PGEM, PGDM, tetranor PGAM and PGDM) are discriminants for this cluster, indicating a high value for these oxylipins and a low activity decreasing them. However, they also decreased 11ß-PGF $2 \alpha$, 15-keto $\mathrm{PGF}_{2 \alpha}$ and $\mathrm{PGE}_{1}$.

Dual cluster: In this cluster, we found compounds with antioxidant and anti-inflammatory activities, such as FA, DHFA, iFA and 3,4-diCQA. Their projections are located on the opposite side for all variables. In this cluster, observations corresponding to the mixed treatment were also projected. The mixture decreased all oxylipins.

The analysis of dissimilarity to determine the distance or the (dis) similarity between each pair of observations organized by chemical structure was performed by using Pearson correlation-based distance measurements, which measure the degree of relationship between two profiles. The order of the dissimilarity matrix is shown in Fig. 5, where blue (scale $=0$ ) corresponds to a small distance between similar treatments and orange (scale $=2$ ) indicates a large distance between treatments. Related to the biological activity, the compounds can be clustered into three categories, A, B or C, which coincide with the structural similarity, with one exception (e.g., 4-coumaric acid; CoA). In particular, cluster A shows a high degree of similarity in terms of the

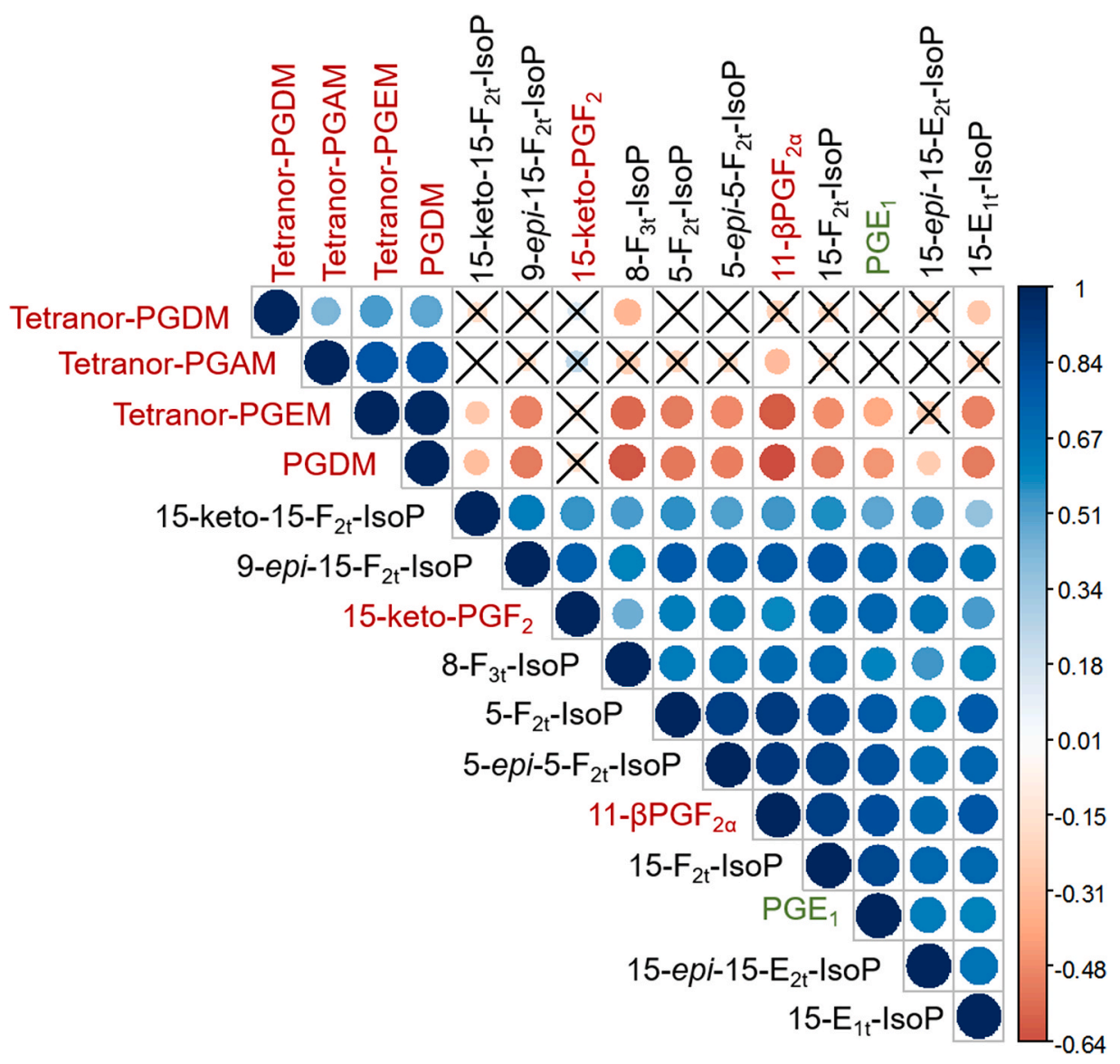

Fig. 3. Correlations between the oxylipins produced by foam cells after phenolic compound treatments. The pairwise Pearson correlation was computed for each pair of variables, and the matrix illustrates the magnitude of correlation for each pair. Blue and brown indicate the positive and negative correlations, respectively. The color intensity and size of the circles represent the strength of the correlation and are shown hierarchically. Isoprostanes (black), inflammatory prostaglandins (red) and anti-inflammatory PGE $_{1}$ (green) were compared. Not Significant correlations $(P>0.05)$ are marked with an X. (For interpretation of the references to color in this figure legend, the reader is referred to the Web version of this article.) 
effect among diCQA isomers, as well as between CoA and diCQAs (antiinflammatory). For cluster $\mathrm{B}$, the degree of similarity is for CQA isomers (antioxidants), as shown in the PCA analysis. On the other hand, most of the phenolic acids (ferulic, dihydroferulic, isoferulic, caffeic and dihydrocaffeic) showed a lesser degree of similarity (or no similarity) with respect to the bioactivity of CQAs and diCQAs (C category). The lack of correspondence of phenolic acids with respect to others can imply two events, low bioactivity or similar bioactivities with respect to diCQAs (or CoA) and CQAs. In other words, the inverse relation pattern between CQA and diCQA treatments suggests that the regulation is probably due to two different mechanisms: antioxidant and anti-inflammation, and most phenolic acids could intervene in both at the same time.

\section{Discussion}

The results of this clinical study indicate that the consumption of
$400 \mathrm{~mL}$ of filtered Coffee A protects lipids against oxidative damage in healthy adults (Table 1). The lack of effect of Coffee B is probably due to the lower content of CGAs. Other studies have analyzed the effect of coffee consumption on $15-\mathrm{F}_{2 \mathrm{t}}$-IsoP $\left(8\right.$-iso- $\mathrm{PGF}_{2 \alpha}$ ). Hoelzl et al. found a significant decrease in the urinary levels of $\mathrm{F}_{2 \mathrm{t}}$-IsoP $(-15.3 \%)$ after instant coffee consumption ( $800 \mathrm{~mL} /$ day; $1200 \mathrm{mg}$ of CGAs; 5 days) [27]. Kempf et al. detected a reduction of $3.8 \%(P>0.05)$ and $16 \%$ $(P>0.05)$ after the intake of $600 \mathrm{~mL}$ and $1200 \mathrm{~mL}$ of filtered coffee for 1 month, respectively [28]; unfortunately, in this study, the CGAs content were not reported. Contrary to our results, Mursu et al. did not find significant changes in plasma levels of $\mathrm{F}_{2}$-IsoPs when evaluating the effect of $80.9 \mathrm{mg}$ of CGAs provided by $100 \mathrm{~mL}$ of coffee, neither after acute (0, 1 and 2 cups; $1.5 \mathrm{~h})$ nor after long-term interventions ( 3 or 6 cups/day for three weeks) [26]. In the same way, the study of Correa et al. used two doses that provided high concentrations of CGAs ( $675 \mathrm{mg}$ and $1073 \mathrm{mg} ; 482 \mathrm{~mL}$ ) but did not show significant changes 4 weeks after the intervention; the authors explain that the lack of change

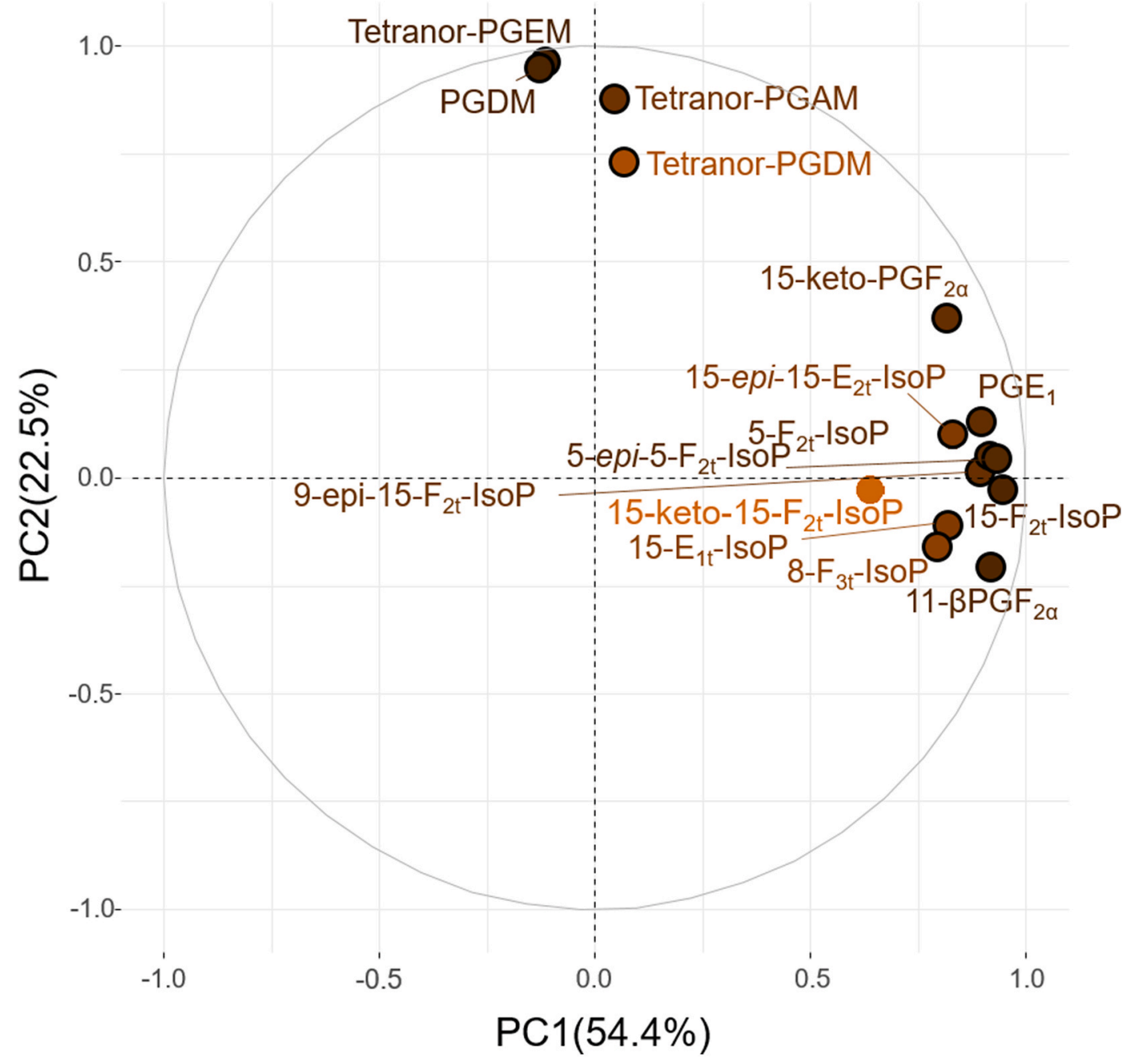

(a)

Fig. 4. Principal component analysis of macrophage responses to phenolic compounds and oxLDL. The data matrix (Supplementary Table S3) satisfies the KaiserMeyer-Olkin criterion with a value of 0.8 . PC1 vs. PC2, containing $76.9 \%$ of the variance explained. A) The variables (oxylipins) correlate significantly $(P<0.001$ ) with PC1 or PC2 (Supplementary Table S5). The brown color intensity indicates a high quality of representation. B) PC1 vs. PC2. Previously, the optimal number of clusters was calculated (data not shown), and the individuals were grouped by activities (antioxidant, anti-inflammatory and dual effects) and induction or positive control (C+). A mixture (mix) of caffeic (CA), dihydrocaffeic (DHCA), ferulic (FA), isoferulic (iFA), dihydroferulic (DHFA), 4-coumaric (CoA) acids, caffeoylquinic acids (3-CQA, 4-CQA and 5-CQA) and dicaffeoylquinic acids (3,4-diCQA, 3,5-diCQA and 4,5-diCQA) was also evaluated. The circle size shows a high quality of representation. Five experimental replicates of each compound were evaluated. (For interpretation of the references to color in this figure legend, the reader is referred to the Web version of this article.) 


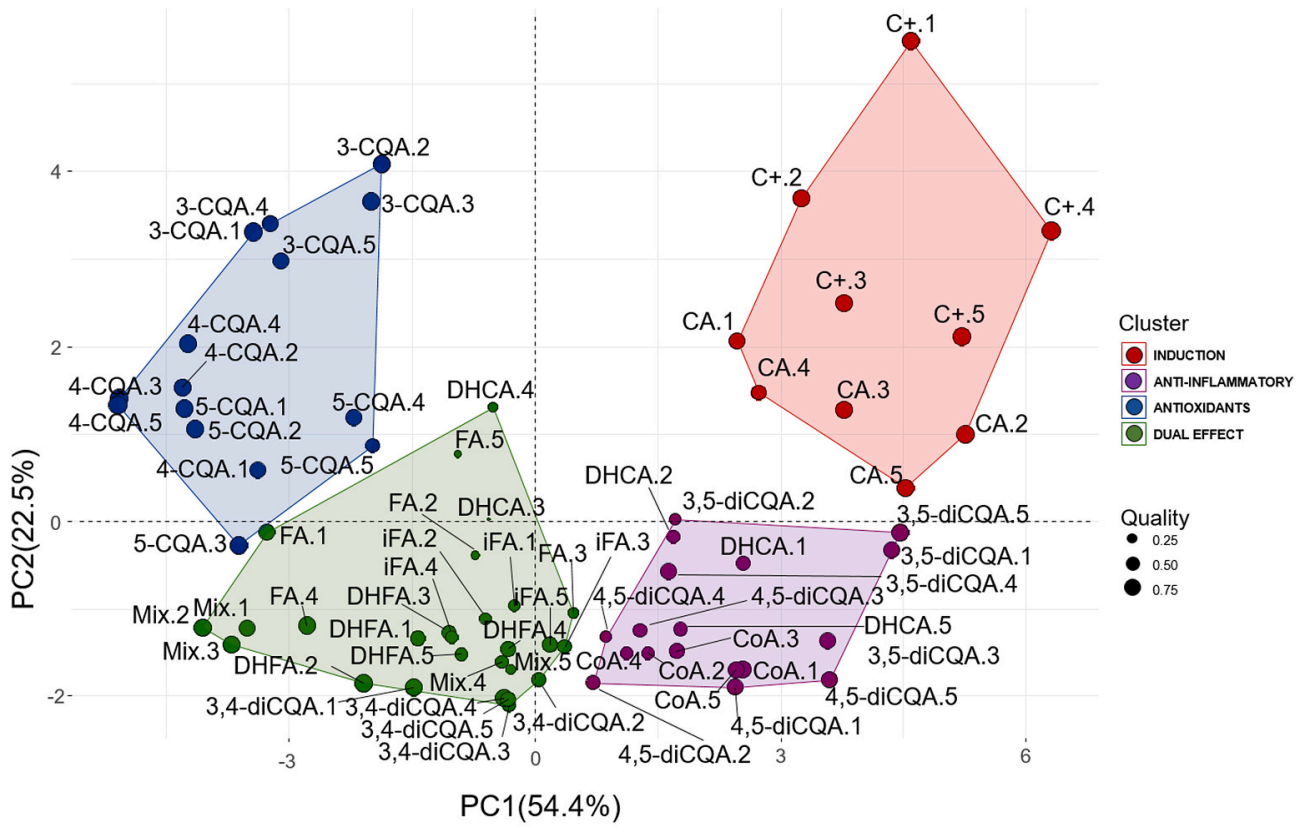

(b)

Fig. 4. (continued)

was probably due to the short time of exposure. On the other hand, the type of coffee used and the methodology applied for determining the $15-\mathrm{F}_{2 \mathrm{t}}$-IsoP, which was immunoassays, limit us the possibility of comparison [35]. In the present study, we report for the first time the reduction of $\mathrm{F}_{2}$-dihomo-IsoPs by coffee consumption, which are specific indices of oxidative stress and markers of biological oxidative damage involving specific adrenic acid oxidation forms. These isoprostanoids have been reported as markers in neurological conditions such as Alzheimer's, Rett syndrome, Down's syndrome, and epilepsy [6]. Thus, the reduction of 7 - and 17-series $\mathrm{F}_{2}$-dihomo-IsoP indicates protection against oxidative neurodegeneration.

Related to inflammation, the decrease in some PGs and their metabolites suggests an anti-inflammatory effect of both coffees, A and B, after 8 weeks of intervention. However, the impact on inflammation was stronger for Coffee A (Table 2). In contrast, in the control group, a significant increase in some PGs was observed after 8 weeks of intervention (11ß-PGF $2 \alpha$ and tetranor-PGDM). PGs are mediators of acute inflammation, and they also function in the transition and maintenance of chronic inflammation, being relevant in the context of CVD [58]. Currently, $\mathrm{PGE}_{2}$ is one of the most widely investigated and used markers of inflammation, disease state, and therapeutic effectiveness [59]. However, due to its fast metabolism, direct measurement of $\mathrm{PGE}_{2}$ in biological samples is difficult [60]; therefore, tetranor-PGEM and tetranor-PGAM (a dehydration product of tetranor-PGEM) are the main urinary metabolites that serve as indirect markers of $\mathrm{PGE}_{2}$ biosynthesis [61], and all of them were reduced after 8 weeks of coffee intake. PGE 2 is involved in the relaxation and contraction of various types of smooth muscles [59]. The activity of this PG depends on the specific prostaglandin E receptors (EPs) [62], which can induce hypertension and brain injury $\left(\mathrm{PGE}_{2}\right.$-EP1) and thromboembolism $\left(\mathrm{PGE}_{2}\right.$-EP3) by vasoconstriction. In contrast, $\mathrm{PGE}_{2}-\mathrm{EP} 2$ or $\mathrm{PGE}_{2}-\mathrm{EP} 4$ can reduce cardiac injury ischemia/reperfusion, and $\mathrm{PGE}_{2}-\mathrm{EP} 2$ decreases hypertension and brain injury by vasodilation [62].

On the other hand, three $\mathrm{PGD}_{2}$ metabolites, PGDM and tetranorPGDM, decreased after coffee consumption; although $\mathrm{PGD}_{2}$ was not detected, its metabolites are an indirect determination of $\mathrm{PGD}_{2}$ in human urine [55]. The evidence showed that exacerbated production of $\mathrm{PGD}_{2}$ metabolites could be directly related an increasing risk of CVD [59]. Finally, the consumption of coffee also resulted in a decrease in
$\mathrm{PGE}_{1}$, known as an anti-inflammatory compound, a vasodilator, a regulator of the immune system, a protector of vulnerable plaques and a neovascularization enhancer $[63,64]$.

Contrary to the effects on oxylipins observed for coffee consumption, an unexpected neutral effect was observed on LDL susceptibility to oxidation. A possible reason is that the sample collection at the end of the intervention ( 8 weeks) was taken $21 \mathrm{~h}$ after the last consumption. Although some studies have shown that coffee consumption protects LDL against oxidation [21,22], others did not reveal changes in oxLDL levels after coffee intake $[27,65]$.

Related to the in vitro approach, the injury generated by the OxLDLmacrophage that includes massive oxLDL uptake, ROS production, and overexpression of oxLDL receptors is reduced by PAs and CGAs treatments (Fig. 2). Previous studies have shown that flavonoids block oxLDL uptake, at least in part, by reducing CD36 or SR-A expression on macrophages [66,67]. The increased ROS concentration in macrophages due to oxLDL was significantly decreased when treated with antioxidants (Fig. 2C). Similar to CD36 inhibition (Figs. 2D), 4,5diCQA, DHCA and CoA exhibited an inhibitory effect on ROS production. The relevance of ROS and CD36 intervention is that CD36 is also an important receptor for oxLDL-mediated ROS production [53]. A similar effect has been observed for a few flavonoids and protocatechuic acid [67-71]. Moreover, the mix also inhibited oxLDL uptake via downregulation of CD36, SR-A and LOX-1.

Because oxLDL is a strong inducer of oxylipins, we used the oxLDL THP1-macrophage interaction model to evaluate the effect of some phenolic compounds that are absorbed in the organism after coffee intake. To date, the biological role of all IsoPs analyzed in macrophages and foam cells is limited to $15-\mathrm{F}_{2 \mathrm{t}}$-IsoP [71]. Moreover, studies showing the effects of natural compounds from diet reducing their production are still scarce; nevertheless, the literature is consistently describing 15$\mathrm{F}_{2 \mathrm{t}}$-IsoP as a vasoconstrictor in several vascular systems (tissues from animal or human sources) such as the kidney, liver, heart, lung, smooth muscle, peripheral lymphatics and airways [4], as well in human vessels where $15-\mathrm{F}_{2 \mathrm{t}}$-IsoP, 9-epi-15- $\mathrm{F}_{2 \mathrm{t}}$-IsoP (8-iso- $\mathrm{PGF}_{2 \beta}$ ) and $15-\mathrm{E}_{1 \mathrm{t}}$-IsoP (8-iso-PGE ${ }_{1}$ ) had similar activities [72]. In this study, some of the oxylipins detected in humans had already been observed in vitro [36]: four IsoPs (15- $\mathrm{F}_{2 \mathrm{t}}$-IsoP, 5- $\mathrm{F}_{2 \mathrm{t}}$-IsoP, 5-epi-5- $\mathrm{F}_{2 \mathrm{t}}$-IsoP, and 15- $\mathrm{E}_{1 \mathrm{t}}$-IsoP) and five PGs (tetranor-PGAM, PGDM, $11 \beta-\mathrm{PGF}_{2 \alpha}$, tetranor PGDM and 


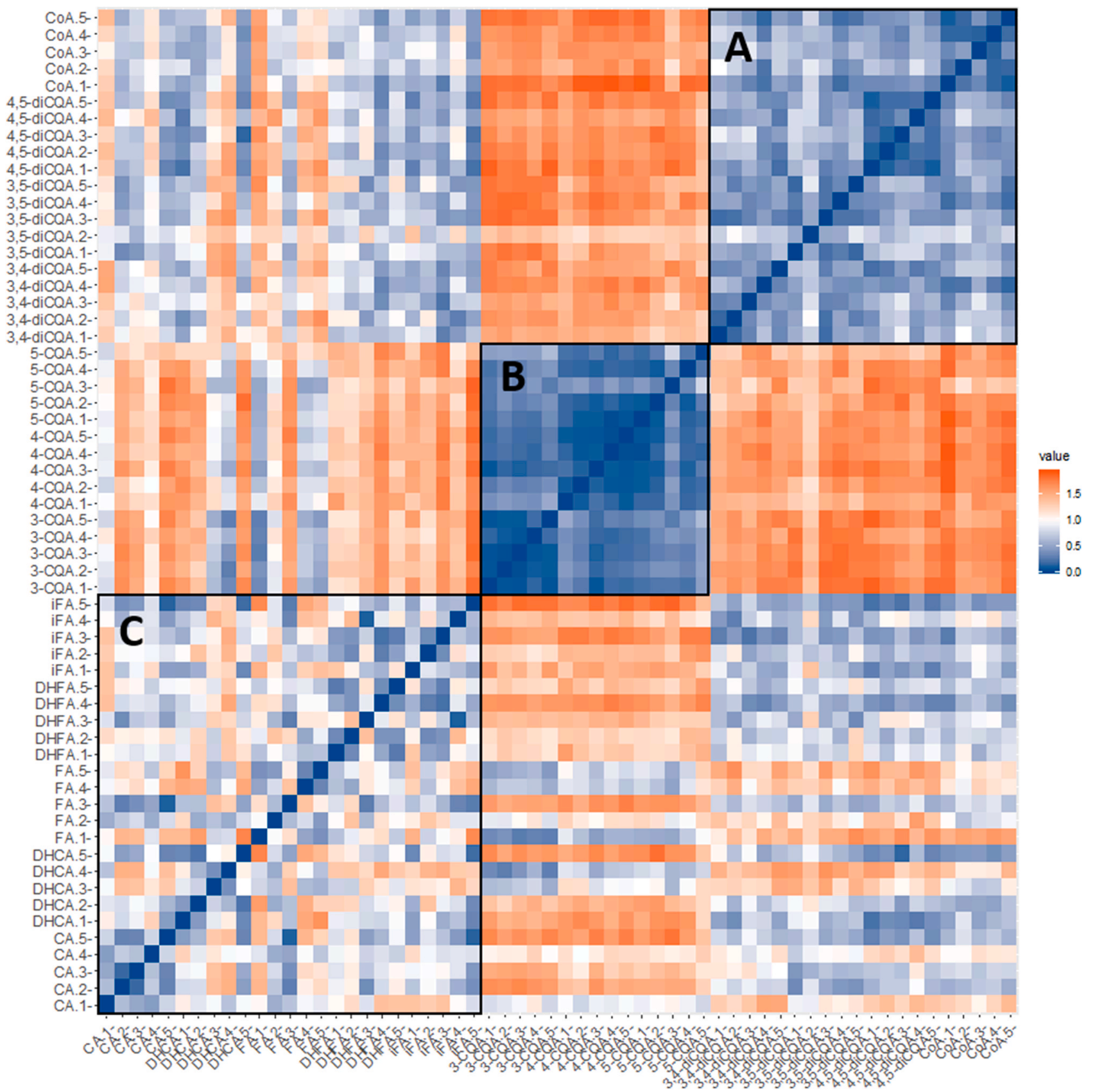

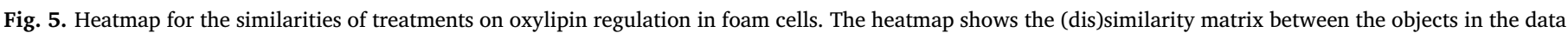

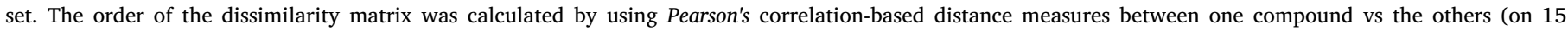

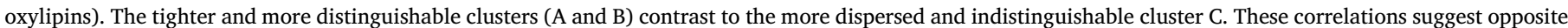

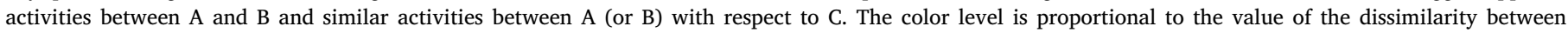

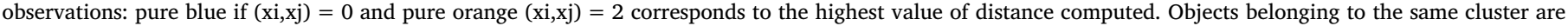
displayed in consecutive order. (For interpretation of the references to color in this figure legend, the reader is referred to the Web version of this article.)

$\mathrm{PGE}_{1}$ ). On the other hand, 8- $\mathrm{F}_{3 \mathrm{t}^{-}} \mathrm{Iso}$, 9-epi-15- $\mathrm{F}_{2 \mathrm{t}}-\mathrm{IsoP}$, 15-keto-15- $\mathrm{F}_{2 \mathrm{t}^{-}}$ IsoP, 15-epi-15- $\mathrm{E}_{2 \mathrm{t}}$-IsoP and $15-\mathrm{keto} \mathrm{PGF}_{2 \alpha}$ were only detected in the foam cell model [36]. Remarkably, CQAs followed by FA, DHFA and iFA reduced F- and E-IsoP levels in the oxLDL interaction THP1-macrophage model.

Related to inflammation, the overproduction of $\mathrm{PGE}_{2}$ metabolites tetranor-PGAM, tetranor-PGEM and $15-$ keto-PGF $_{2 \alpha}$ was strongly reduced by diCQAs, DHCA and CoA. Other studies have shown that FA, iFA, CoA, 5-CQA and diCQAs downregulate COX-2, NF- $\mathrm{kB}$ and inducible nitric oxide synthase (iNOS) expression and JNK/AP-1 activation, as well as inhibit inflammatory mediators such as $\mathrm{PGE}_{2}$, nitric oxide (NO) and pro-inflammatory cytokines (including IL-1 $\beta$, TNF- $\alpha$ and IL-6); the above was observed in lipopolysaccharide (LPS)-stimulated RAW 264.7 murine macrophages [73-77]. In addition, CGAs have been observed to have an impact over transcription factors and enzymes that regulate lipid metabolism mediated by increasing peroxisome proliferative-activated receptor alpha (PPAR $\alpha$ ) expression [78]. Regarding PGD and its metabolites, PGDM was the most relevant inflammatory marker in macrophages activated by oxLDL (Supplementary Table S3). Notably, diCQAs decreased PGDM levels by approximately $80 \%$. As expected, similar activity was also observed for tetranor-PGDM, since it is derived from PGDM metabolism [55]. In general, significant inhibitory activity on PGDM, tetranor-PGEM and tetranor PGAM by diCQAs followed by FA, DHFA and iFA was observed 
(Figs. 3-5). Interestingly, 11ß-PGF $2 \alpha$, one of the main PGD metabolites, was mainly decreased by CQA , followed by 3,4-diCQA, FA, DHFA and iFA. This change in the activity profile by phenolic compounds can be due to $11 \beta-\mathrm{PGF}_{2 \alpha}$ being formed through several pathways. $11 \beta-\mathrm{PGF}_{2 \alpha}$ is produced from $\mathrm{PGH}_{2}$ and/or $\mathrm{PGD}_{2}$ by aldo-keto reductases [79], which are pharmacological targets (COX independent) [80] and can be inhibited more efficiently by CQAs. Collectively, these results demonstrate that CGAs target multiple innate inflammatory pathways related to PGE and PGD that are known in macrophages during atherosclerosis [2]. Finally, foam cells overexpress salvage pathways against the injury caused by oxLDL $[13,36,81]$ through the expression of enzymatic oxidation pathways for producing $\mathrm{PGE}_{1}$, an anti-inflammatory $\mathrm{PG}$ $[62,63,79,82]$. Most of the phenolic compounds evaluated significantly decreased PGE 1 (Supplementary Table S3, Figs. 3 and 5), probably due to the global positive impact on oxidative stress and inflammation.

Our findings suggest that coffee antioxidants can modulate different pathways related to oxylipin production. Most of the PGs reduced in our study after coffee consumption, implicate $\beta$-oxidation steps on PGE and PGD [1,3,4,6-9]. The decrease in some IsoPs, indeed involves the modulation of the spontaneous oxidation of arachidonic [10,11], dihomo gamma linolenic [12], eicosapentanoic and adrenic acids [13]. $\mathrm{Up}$ to now, only $\mathrm{E}_{2 \mathrm{t}}$-IsoPs, $\mathrm{E}_{1 \mathrm{t}}$-IsoPs and $15-\mathrm{F}_{2 \mathrm{t}}$-IsoP (including its isomer 9-epi-15- $\mathrm{F}_{2 \mathrm{t}}$-IsoP and its $\beta$-/ $\omega$-oxidized metabolites 15 -keto-15$\mathrm{F}_{2 \mathrm{t}}$-IsoP and 2,3-dinor-15- $\mathrm{F}_{2 \mathrm{t}}$-IsoP) have been reported as pro-inflammatory and vasoconstriction mediators [14-18], while the biological functions of the 5- $\mathrm{F}_{2 \mathrm{t}}$-IsoPs and dihomo-IsoPs are still unknown. Only $15-\mathrm{F}_{2 \mathrm{t}}$-IsoP has been reported as an inductor of foam cell formation key in atherogenesis progression and plaque destabilization $[19,20]$.

Finally, some limitations should be noted. The study lacks placebo, therefore the intervention was not blind for participants. Nevertheless, the groups A and B did not know what kind of coffee they received. On the other hand, oxylipins and oxLDL were not used to calculate the sample size, since the study was initially designed to observe changes in plasma AC after coffee intake. Thanks to our study, this information will be available for subsequent nutritional interventions with coffee or similar foods.

In summary, oxylipins are reliable markers of lipid peroxidation and inflammation, are increased under conditions of oxidative stress and are associated with an increased risk of a number of diseases, including neurological disorders, CVDs, lung diseases, and renal dysfunction among others $[3,4,9]$. Their reduction strongly suggests that CGAs and phenolic compounds in coffee protect lipids against oxidation and have a positive effect against the harmful effects of oxidative stress and inflammation in CVD progression and development.

\section{Conclusions}

This study provides clinical and in vitro evidence that CGAs and phenolic compounds from coffee beverages regulate oxylipins, which are well-accepted biomarkers of oxidative stress and inflammation in CVD. In our clinical trial, the intake of two filtered coffees, Coffees A (787 mg CGAs/day) and B (407 mg CGAs/day) for 8 weeks reduced the urinary levels of oxylipins, with Coffee A being more active, which can be explained by its CGA content. The intake of both coffees had a neutral effect on plasmatic oxLDL levels. However, when the atherogenic effects of oxLDL were treated with CGAs and phenolic compounds in an in vitro foam cell model, oxylipin production (many of them observed in the clinical study) also decreased. The evaluation of 35 biomarkers, including $\mathrm{F}_{2^{-}}, \mathrm{F}_{3^{-}}, \mathrm{E}_{1^{-}}$, and $\mathrm{E}_{2^{-}}$IsoPs, dihomo-IsoPs, inflammatory and anti-inflammatory PGs, suggested that coffee intake causes significant protective effects against the damage mediated by inflammation and oxidative stress on lipids. Our results contribute scientific evidence that supports the idea that coffee consumption helps reduce risk factors for CVD. It is a pivotal challenge to unravel the crossregulation among the different cellular actors and enzymatic pathways involved in oxylipin synthesis in humans. Furthermore, the scarce information available on the urinary lipid composition in healthy subjects on a regular diet is a drawback for achieving comprehensive insight into the effect of dietary polyphenols on lipidome. This study could be enlarged using new lipid metabolites like those obtained from lipoxygenase pathway and fatty acid esters of hydroxy-fatty acids (FAHFAs) to achieve new insights of coffee effects on the respiratory system (inflammation) and also on glucose metabolism disorders (like diabetes), two key points associated with the co-morbidity of the recent Covid-19 pandemic and other infectious diseases where the diet play a relevant role on the prevention of these type of diseases linked to the immunological system $[83,84]$.

\section{Author contributions}

Conceptualization KM-D, RA-Q, AG-I and OJL-G; methodology KMD, RA-Q, AG-I, SM, OJL-G, CO, TD, and J-MG; formal analysis OJL-G and KM-D; investigation OJL-G, SM, RA-Q and KM-D; writing-original draft preparation, OJL-G and KM-D; writing - review and editing KM-D, RA-Q, AG-I, SM, CO, TD, and J-MG; project supervision and administration, KM-D; funding acquisition, KM-D.

\section{Acknowledgments}

The authors thank the volunteers who participated in the clinical trial. This study was financed by COLCAFÉ S.A.S, the Vidarium Research Center and the University of Antioquia. The authors are grateful for the support of COLCIENCIAS through grant no. 528-2011 for doctoral students, the young researchers and innovators program (617-2013) and to the "Fundación Séneca de la Región de Murcia" Grupo de Excelencia 19900/GERM/15. This work is included in the framework of the collaboration between the Spanish Research Council (CEBAS-CSIC) and CNRS by "Projets Internationaux de Cooperation Scientifique" (PICS-2015-261141). They also thank the Ibero-American Programme for Science, Technology and Development (CYTED) - Action 112RT0460 CORNUCOPIA and the project i-link 0846 (i-Link +2013 CSIC).

\section{Appendix A. Supplementary data}

Supplementary data to this article can be found online at https:// doi.org/10.1016/j.freeradbiomed.2020.07.020.

\section{References}

[1] S.S. Davies, L.J. Roberts II, F-2 isoprostanes as an indicator and risk factor for coronary heart disease, Free Radic. Biol. Med. 50 (2011) 559-566, https://doi.org/ 10.1016/j.freeradbiomed.2010.11.023.

[2] S. Gleim, J. Stitham, W.H. Tang, K.A. Martin, J. Hwa, An eicosanoid-centric view of atherothrombotic risk factors, Cell. Mol. Life Sci. 69 (2012) 3361-3380, https://doi. org /10.1007/s00018-012-0982-9.

[3] J.M. Galano, J.C. Lee, C. Gladine, B. Comte, J.Y. Le Guennec, C. Oger, T. Durand, Non-enzymatic cyclic oxygenated metabolites of adrenic, docosahexaenoic, eicosapentaenoic and alpha-linolenic acids; bioactivities and potential use as biomarkers, Biochim. Biophys. Acta 1851 (2015) 446-455, https://doi.org/10.1016/j. bbalip.2014.11.004 S1388-1981(14)00232-7 [pii].

[4] J.-M. Galano, Y.Y. Lee, C. Oger, C. Vigor, J. Vercauteren, T. Durand, M. Giera, J.C.Y. Lee, Isoprostanes, neuroprostanes and phytoprostanes: an overview of 25years of research in chemistry and biology, Prog. Lipid Res. 68 (2017) 83-108, https://doi. org/10.1016/j.plipres.2017.09.004.

[5] X. Wang, H. Lin, Y. Gu, Multiple roles of dihomo- $\gamma$-linolenic acid against proliferation diseases, Lipids Health Dis. 11 (2012) 25, https://doi.org/10.1186/1476 511X-11-25.

[6] C. Signorini, C. De Felice, J.-M. Galano, C. Oger, S. Leoncini, A. Cortelazzo, L. Ciccoli, T. Durand, J. Hayek, J.C.-Y. Lee, Isoprostanoids in clinical and experimental neurological disease models, Antioxidants (Basel, Switzerland) 7 (2018) 88, https://doi.org/10.3390/antiox7070088.

[7] M.A. Nayeem, Role of oxylipins in cardiovascular diseases, Acta Pharmacol. Sin. 39 (2018) 1142-1154, https://doi.org/10.1038/aps.2018.24.

[8] A. Nishibe, Y. Kijima, M. Fukunaga, N. Nishiwaki, T. Sakai, Y. Nakagawa, T. Hata, Increased isoprostane content in coronary plaques obtained from vulnerable patients, Prostagl. Leukot. Essent. Fat. Acids 78 (2008) 257-263, https://doi.org/10. 
1016/j.plefa.2008.03.001.

[9] G.L. Milne, H. Yin, K.D. Hardy, S.S. Davies, L.J. Roberts, Isoprostane generation and function, Chem. Rev. 111 (2011) 5973-5996, https://doi.org/10.1021/cr200160h.

[10] I. Levitan, S. Volkov, P.V. Subbaiah, Oxidized LDL: Diversity, patterns of recognition, and pathophysiology, Antioxidants Redox Signal. 13 (2010) 39-75, https:// doi.org/10.1089/ars.2009.2733.

[11] V.V. Kunjathoor, M. Febbraio, E.A. Podrez, K.J. Moore, L. Andersson, S. Koehn, J.S. Rhee, R. Silverstein, H.F. Hoff, M.W. Freeman, Scavenger receptors class A-I/II and CD36 are the principal receptors responsible for the uptake of modified low density lipoprotein leading to lipid loading in macrophages, J. Biol. Chem. 277 (2002) 49982-49988, https://doi.org/10.1074/jbc.M209649200.

[12] A. Pirillo, G.D. Norata, A.L. Catapano, LOX-1, OxLDL, and atherosclerosis, Mediat. Inflamm. 2013 (2013) 12, https://doi.org/10.1155/2013/152786.

[13] K.J. Moore, I. Tabas, Macrophages in the pathogenesis of atherosclerosis, Cell 145 (2011) 341-355, https://doi.org/10.1016/j.cell.2011.04.005.

[14] A. Crippa, A. Discacciati, S.C. Larsson, A. Wolk, N. Orsini, Coffee consumption and mortality from all causes, cardiovascular disease, and cancer: a dose-response metaanalysis, Am. J. Epidemiol. 180 (2014) 763-775, https://doi.org/10.1093/aje/ kwu194.

[15] M. Ding, S.N. Bhupathiraju, A. Satija, R.M. van Dam, F.B. Hu, Long-term coffee consumption and risk of cardiovascular disease: a systematic review and a doseresponse meta-analysis of prospective cohort studies, Circulation 129 (2014) 643-659, https://doi.org/10.1161/CIRCULATIONAHA.113.005925.

[16] S.A. Rebello, R.M. van Dam, Coffee consumption and cardiovascular health: getting to the heart of the matter, Curr. Cardiol. Rep. 15 (2013) 403, https://doi.org/10. 1007/s11886-013-0403-1.

[17] M. Quiñones, M. Miguel, A. Aleixandre, Beneficial effects of polyphenols on cardiovascular disease, Pharmacol. Res. 68 (2013), https://doi.org/10.1016/j.phrs. 2012.10.018.

[18] A. Tresserra-Rimbau, E.B. Rimm, A. Medina-Remón, M.A. Martínez-González, M.C. López-Sabater, M.I. Covas, D. Corella, J. Salas-Salvadó, E. Gómez-Gracia, J. Lapetra, F. Arós, M. Fiol, E. Ros, L. Serra-Majem, X. Pintó, M.A. Muñoz, A. Gea, V. Ruiz-Gutiérrez, R. Estruch, R.M. Lamuela-Raventós, Polyphenol intake and mortality risk: a re-analysis of the PREDIMED trial, BMC Med. 12 (2014) 1, https:// doi.org/10.1186/1741-7015-12-77.

[19] M. Renouf, P.A. Guy, C. Marmet, A.L. Fraering, K. Longet, J. Moulin, M. Enslen, D. Barron, F. Dionisi, C. Cavin, G. Williamson, H. Steiling, Measurement of caffeic and ferulic acid equivalents in plasma after coffee consumption: small intestine and colon are key sites for coffee metabolism, Mol. Nutr. Food Res. 54 (2010) 760-766, https://doi.org/10.1002/mnfr.200900056.

[20] A. Stalmach, G. Williamson, A. Crozier, Impact of dose on the bioavailability of coffee chlorogenic acids in humans, Food Funct. 5 (2014) 1727-1737, https://doi. org/10.1039/c4fo00316k.

21] K. Nagy, L. Actis-Goretta, K. Redeuil, D. Barron, R. Fumeaux, F. Giuffrida, C. CruzHernandez, F. Destaillats, Identification of cholesteryl ester of ferulic acid in human plasma by mass spectrometry, J. Chromatogr. A 1301 (2013) 162-168, https://doi. org/10.1016/j.chroma.2013.05.078 S0021-9673(13)00875-3 [pii].

[22] F. Natella, M. Nardini, F. Belelli, C. Scaccini, Coffee drinking induces incorporation of phenolic acids into LDL and increases the resistance of LDL to ex vivo oxidation in humans, Am. J. Clin. Nutr. 86 (2007) 604-609 86/3/604 [pii].

23] O.J. Lara-Guzmán, R. Álvarez-Quintero, E. Osorio, M. Naranjo-Cano, K. MuñozDurango, GC/MS method to quantify bioavailable phenolic compounds and antioxidant capacity determination of plasma after acute coffee consumption in human volunteers, Food Res. Int. 89 (2016), https://doi.org/10.1016/j.foodres.2016.07. 020.

[24] F.X. Chen, L.K. Wang, [Effect of ferulic acid on cholesterol efflux in macrophage foam cell formation and potential mechanism], Zhongguo Zhongyao Zazhi 40 (2015) 533-537.

[25] C. Wu, H. Luan, X. Zhang, S. Wang, X. Sun, P. Guo, Chlorogenic acid protects against atherosclerosis in ApoE-/- mice and promotes cholesterol efflux from RAW264.7 macrophages, PloS One 9 (2014) e95452, , https://doi.org/10.1371/ journal.pone.0095452 [doi]PONE-D-13-42504 [pii].

[26] J. Mursu, S. Voutilainen, T. Nurmi, G. Alfthan, J.K. Virtanen, T.H. Rissanen, P. Happonen, K. Nyyssonen, J. Kaikkonen, R. Salonen, J.T. Salonen, The effects of coffee consumption on lipid peroxidation and plasma total homocysteine concentrations: a clinical trial, Free Radic. Biol. Med. 38 (2005) 527-534, https://doi. org/10.1016/j.freeradbiomed.2004.11.025.

[27] C. Hoelzl, S. Knasmuller, K.-H. Wagner, L. Elbling, W. Huber, N. Kager, F. Ferk, V. Ehrlich, A. Nersesyan, O. Neubauer, A. Desmarchelier, M. Marin-Kuan, T. Delatour, C. Verguet, C. Bezencon, A. Besson, D. Grathwohl, T. Simic, M. Kundi, B. Schilter, C. Cavin, Instant coffee with high chlorogenic acid levels protects humans against oxidative damage of macromolecules, Mol. Nutr. Food Res. 54 (2010) 1722-1733, https://doi.org/10.1002/mnfr.201000048.

[28] K. Kempf, C. Herder, I. Erlund, H. Kolb, S. Martin, M. Carstensen, W. Koenig, J. Sundvall, S. Bidel, S. Kuha, J. Tuomilehto, Effects of coffee consumption on subclinical inflammation and other risk factors for type 2 diabetes: a clinical trial, Am. J. Clin. Nutr. 91 (2010) 950-957, https://doi.org/10.3945/ajcn.2009.28548.

[29] T.A. Correa, M.P. Monteiro, T.M. Mendes, D.M. Oliveira, M.M. Rogero, C.I. Benites, C.G. Vinagre, B.M. Mioto, D. Tarasoutchi, V.L. Tuda, L.A. Cesar, E.A. Torres, Medium light and medium roast paper-filtered coffee increased antioxidant capacity in healthy volunteers: results of a randomized trial, Plant Foods Hum. Nutr. 67 (2012) 277-282, https://doi.org/10.1007/s11130-012-0297-x.

[30] M. Gabbs, S. Leng, J.G. Devassy, M. Monirujjaman, H.M. Aukema, Advances in our understanding of oxylipins derived from dietary PUFAs, Adv. Nutr. 6 (2015) 513-540, https://doi.org/10.3945/an.114.007732.

[31] S. Medina, R. Dominguez-Perles, R. Cejuela-Anta, D. Villano, J.M. Martinez-Sanz,
P. Gil, C. Garcia-Viguera, F. Ferreres, J.I. Gil, A. Gil-Izquierdo, Assessment of oxidative stress markers and prostaglandins after chronic training of triathletes, Prostag. Other Lipid Mediat. 99 (2012) 79-86, https://doi.org/10.1016/j. prostaglandins.2012.07.002

[32] L.A. Garcia-Flores, S. Medina, C. Gomez, C.E. Wheelock, R. Cejuela, J.M. MartinezSanz, C. Oger, J.-M. Galano, T. Durand, A. Hernandez-Saez, F. Ferreres, A. GilIzquierdo, Aronia-citrus juice (polyphenol-rich juice) intake and elite triathlon training: a lipidomic approach using representative oxylipins in urine, Food Funct. 9 (2018) 463-475, https://doi.org/10.1039/c7fo01409k.

[33] S. Medina, R. Domínguez-Perles, J.I.I. Gil, F. Ferreres, A. Gil-Izquierdo, Metabolomics and the diagnosis of human diseases -A guide to the markers and pathophysiological pathways affected, Curr. Med. Chem. 21 (2014) 823-848, https://doi.org/10.2174/0929867320666131119124056.

[34] D. Turck, J.-L. Bresson, B. Burlingame, T. Dean, S. Fairweather-Tait, M. Heinonen, K.I. Hirsch-Ernst, I. Mangelsdorf, H.J. McArdle, A. Naska, M. Neuhäuser-Berthold, G. Nowicka, K. Pentieva, Y. Sanz, A. Sjödin, M. Stern, D. Tomé, H. Van Loveren, M. Vinceti, P. Willatts, A. Martin, J.J. Strain, L. Heng, S. Valtueña Martínez, A. Siani, Guidance for the scientific requirements for health claims related to antioxidants, oxidative damage and cardiovascular health, EFSA J. 16 (2018) e05136, https://doi.org/10.2903/j.efsa.2018.5136.

[35] R.P. Mensink, A. Aro, E.D. Hond, J.B. German, B.A. Griffin, H.-U. Ter Meer, M. Mutanen, D. Pannemans, W. Stahl, PASSCLAIM - diet-related cardiovascular disease, Eur. J. Nutr. 42 (2003) I/6-I/27, https://doi.org/10.1007/s00394-003$1102-2$.

[36] O.J. Lara-Guzmán, Á. Gil-Izquierdo, S. Medina, E. Osorio, R. Álvarez-Quintero, N. Zuluaga, C. Oger, J.-M. Galano, T. Durand, K. Muñoz-Durango, Oxidized LDL triggers changes in oxidative stress and inflammatory biomarkers in human macrophages, Redox Biol. 15 (2018) 1-11, https://doi.org/10.1016/j.redox.2017.11. 017.

[37] G.M. Agudelo-Ochoa, I.C. Pulgarín-Zapata, C.M. Velásquez-Rodriguez, M. DuqueRamírez, M. Naranjo-Cano, M.M. Quintero-Ortiz, O.J. Lara-Guzmán, K. MuñozDurango, Coffee consumption increases the antioxidant capacity of plasma and has No effect on the lipid profile or vascular function in healthy adults in a randomized controlled trial, J. Nutr. 146 (2016) 524-531, https://doi.org/10.3945/jn.115. 224774

[38] N. Moura-Nunes, D. Perrone, A. Farah, C.M. Donangelo, The increase in human plasma antioxidant capacity after acute coffee intake is not associated with endogenous non-enzymatic antioxidant components, Int. J. Food Sci. Nutr. 60 (Suppl 6) (2009) 173-181, https://doi.org/10.1080/09637480903158893.

[39] I. Liakh, A. Pakiet, T. Sledzinski, A. Mika, Methods of the analysis of oxylipins in biological samples, Molecules 25 (2020) 349, https://doi.org/10.3390/ molecules 25020349 .

[40] T. Durand, J.L. Cracowski, A. Guy, J.C. Rossi, Syntheses and preliminary pharmacological evaluation of the two epimers of the 5-F2t-isoprostane, Bioorg. Med. Chem. Lett 11 (2001) 2495-2498 S0960-894X(01)00473-5 [pii].

[41] T. Durand, A. Guy, J.-P. Vidal, J.-C. Rossi, Total synthesis of (15R)- and (15S)-F2tisoprostanes by a biomimetic process using the cyclization of acyclic dihydroxylated octa-5,7-dienyl radicals, J. Org. Chem. 67 (2002) 3615-3624, https:// doi.org/10.1021/jo0109624.

[42] T. Durand, O. Henry, J.-P. Vidal, J.-C. Rossi, Synthesis of the two main urinary tetranor metabolites of 15-F2t isoprostane, Tetrahedron Lett. 42 (2001) 4333-4336, https://doi.org/10.1016/S0040-4039(01)00754-7.

[43] A. Guy, C. Oger, J. Heppekausen, C. Signorini, C. De Felice, A. Furstner, T. Durand, J.M. Galano, Oxygenated metabolites of n-3 polyunsaturated fatty acids as potential oxidative stress biomarkers: total synthesis of 8-F3t-IsoP, 10-F4t-NeuroP and [D4]10-F4t-NeuroP, Chemistry 20 (2014) 6374-6380, https://doi.org/10.1002/chem. 201400380 [doi].

[44] C. Oger, V. Bultel-Ponce, A. Guy, L. Balas, J.-C. Rossi, T. Durand, J.-M. Galano, The handy use of Brown's P2-Ni catalyst for a skipped diyne deuteration: application to the synthesis of a [D4]-labeled F4t-neuroprostane, Chemistry 16 (2010) 13976-13980, https://doi.org/10.1002/chem.201002304.

[45] C. Oger, V. Bultel-Poncé, A. Guy, T. Durand, J.-M. Galano, Total synthesis of isoprostanes derived from adrenic acid and EPA, Eur. J. Org Chem. (2012) 2621-2634, https://doi.org/10.1002/ejoc.201200070.

[46] S. Medina, R. Domínguez-Perles, J.I. Gil, F. Ferreres, C. García-Viguera, J.M. Martínez-Sanz, A. Gil-Izquierdo, A ultra-pressure liquid chromatography/triple quadrupole tandem mass spectrometry method for the analysis of 13 eicosanoids in human urine and quantitative 24 hour values in healthy volunteers in a controlled constant diet, Rapid Commun. Mass Spectrom. 26 (2012) 1249-1257, https://doi. org $/ 10.1002 / \mathrm{rcm} .6224$

[47] S. Medina, I. De Miguel-Elizaga, C. Oger, J.-M. Galano, T. Durand, M. Martinez Villanueva, M.L.G.-D. Castillo, I. Villegas-Martinez, F. Ferreres, P. MartinezHernandez, A. Gil-Izquierdo, Dihomo-isoprostanes-nonenzymatic metabolites of AdA-are higher in epileptic patients compared to healthy individuals by a new ultrahigh pressure liquid chromatography-triple quadrupole-tandem mass spectrometry method, Free Radic. Biol. Med. 79 (2015) 154-163, https://doi.org/10. 1016/j.freeradbiomed.2014.11.005.

[48] A. Kuksis, W. Pruzanski, Hydrolysis of phosphatidylcholine-isoprostanes (PtdChoIP) by peripheral human group IIA, V and X secretory phospholipases A2 (sPLA2), Lipids 52 (2017) 477-488, https://doi.org/10.1007/s11745-017-4264-z.

[49] V. Wei, T. Simko, The corrplot package, https://cran.r-project.org/web/packages/ corrplot/corrplot.pdf, (2016).

[50] S. Lê, J. Josse, F. Husson, FactoMineR: an R package for multivariate analysis, J. Stat. Software 25 (2008) 1-18, https://doi.org/10.18637/jss.v025.i01.

[51] F. Kassambara, A. Mundt, Factoextra: extract and visualize the results of multivariate data analyses, http://www.sthda.com/english/rpkgs/factoextra, (2017). 
[52] D. Steinberg, The LDL modification hypothesis of atherogenesis: an update, J. Lipid Res. 50 (2009) S376-S381, https://doi.org/10.1194/jlr.R800087-JLR200.

[53] W. Liu, Y. Yin, Z. Zhou, M. He, Y. Dai, OxLDL-induced IL-1beta secretion promoting foam cells formation was mainly via CD36 mediated ROS production leading to NLRP3 inflammasome activation, Inflamm. Res. 63 (2014) 33-43, https://doi.org/ 10.1007/s00011-013-0667-3.

[54] Y. Jiang, M. Wang, K. Huang, Z. Zhang, N. Shao, Y. Zhang, W. Wang, S. Wang, Oxidized low-density lipoprotein induces secretion of interleukin- $1 \beta$ by macrophages via reactive oxygen species-dependent NLRP3 inflammasome activation, Biochem. Biophys. Res. Commun. 425 (2012) 121-126, https://doi.org/10.1016/j. bbrc.2012.07.011.

[55] W.-L. Song, M. Wang, E. Ricciotti, S. Fries, Y. Yu, T. Grosser, M. Reilly, J.A. Lawson, G.A. FitzGerald, Tetranor PGDM, an abundant urinary metabolite reflects biosynthesis of prostaglandin D2 in mice and humans, J. Biol. Chem. 283 (2008) 1179-1188, https://doi.org/10.1074/jbc.M706839200.

[56] T. Yoda, K. Kikuchi, Y. Miki, Y. Onodera, S. Hata, K. Takagi, Y. Nakamura, H. Hirakawa, T. Ishida, T. Suzuki, N. Ohuchi, H. Sasano, K.M. McNamara, 11betaProstaglandin F2alpha, a bioactive metabolite catalyzed by AKR1C3, stimulates prostaglandin F receptor and induces slug expression in breast cancer, Mol. Cell. Endocrinol. 413 (2015) 236-247, https://doi.org/10.1016/j.mce.2015.07.008.

[57] J.W. Lee, H.J. Mok, D.-Y. Lee, S.C. Park, M.S. Ban, J. Choi, C.G. Park, Y.-S. Ahn, K.P. Kim, H.D. Kim, UPLC-MS/MS-Based profiling of eicosanoids in RAW264.7 cells treated with lipopolysaccharide, Int. J. Mol. Sci. 17 (2016) 508, https://doi.org/10. 3390/ijms17040508.

[58] T. Aoki, S. Narumiya, Prostaglandins and chronic inflammation, Trends Pharmacol. Sci. 33 (2012) 304-311, https://doi.org/10.1016/j.tips.2012.02.004

[59] E. Ricciotti, G.A.A. FitzGerald, Prostaglandins and inflammation, arter, Thromb. Vasc. Biol. 31 (2011) 986-1000, https://doi.org/10.1161/ATVBAHA.110.207449 31/5/986 [pii].

[60] B. Watzer, R. Zehbe, S. Halstenberg, C. James Kirkpatrick, C. Brochhausen, Stability of prostaglandin E(2) (PGE (2)) embedded in poly-D,L: -lactide-co-glycolide microspheres: a pre-conditioning approach for tissue engineering applications, J. Mater. Sci. Mater. Med. 20 (2009) 1357-1365, https://doi.org/10.1007/s10856008-3678-9.

[61] J.R. Neale, B.J. Dean, Liquid chromatography-tandem mass spectrometric quantification of the dehydration product of tetranor PGE-M, the major urinary metabolite of prostaglandin E2 in human urine, J. Chromatogr. B Anal. Technol. Biomed. Life Sci. 871 (2008) 72-77, https://doi.org/10.1016/j.jchromb.2008.06.042.

[62] K. Yuhki, F. Kojima, H. Kashiwagi, J. Kawabe, T. Fujino, S. Narumiya, F. Ushikubi, Roles of prostanoids in the pathogenesis of cardiovascular diseases: novel insights from knockout mouse studies, Pharmacol. Ther. 129 (2011) 195-205, https://doi. org/10.1016/j.pharmthera.2010.09.004.

[63] W. Bai, X. Zheng, L. Zhou, H. Li, Prostaglandin E1 dose-dependently promotes stability of atherosclerotic plaque in a rabbit model, Can. J. Physiol. Pharmacol. 90 (2012) 131-139, https://doi.org/10.1139/y11-115.

[64] J. Esaki, H. Sakaguchi, A. Marui, S.C. Bir, Y. Arai, Y. Huang, H. Tsubota, T. Kanaji, T. Ikeda, R. Sakata, Local sustained release of prostaglandin E1 induces neovascularization in murine hindlimb ischemia, Circ. J. 73 (2009) 1330-1336.

[65] M. Mišík, C. Hoelzl, K.-H. Wagner, C. Cavin, B. Moser, M. Kundi, T. Simic, L. Elbling, N. Kager, F. Ferk, V. Ehrlich, A. Nersesyan, M. Dušinská, B. Schilter, S. Knasmüller, Impact of paper filtered coffee on oxidative DNA-damage: results of a clinical trial, Mutat. Res. Mol. Mech. Mutagen. 692 (2010) 42-48, https://doi.org/ 10.1016/j.mrfmmm.2010.08.003.

[66] T.W. Lian, L. Wang, Y.H. Lo, I.J. Huang, M.J. Wu, Fisetin, morin and myricetin attenuate CD36 expression and oxLDL uptake in U937-derived macrophages, Biochim. Biophys. Acta 1781 (2008) 601-609, https://doi.org/10.1016/j.bbalip. 2008.06.009 S1388-1981(08)00126-1 [pii].

[67] J.H. Tabares-Guevara, O.J. Lara-Guzmán, J.A. Londoño-Londoño, J.A. Sierra, Y.M. León-Varela, R.M. álvarez-Quintero, E.J. Osorio, J.R. Ramirez-Pineda, Natural biflavonoids modulate macrophage-oxidized LDL interaction in vitro and promote atheroprotection in vivo, Front. Immunol. 8 (2017), https://doi.org/10.3389/ fimmu.2017.00923.

[68] O.J. Lara-Guzman, J.H. Tabares-Guevara, Y.M. Leon-Varela, R.M. Álvarez, M. Roldan, J.A. Sierra, J.A. Londoño-Londoño, J.R. Ramirez-Pineda, Proatherogenic macrophage activities are targeted by the flavonoid quercetin, J. Pharmacol. Exp.
Therapeut. 343 (2012) 296-306, https://doi.org/10.1124/jpet.112.196147.

[69] R. Varì, B. Scazzocchio, C. Santangelo, C. Filesi, F. Galvano, M. D'Archivio, R. Masella, C. Giovannini, Protocatechuic acid prevents oxLDL-induced apoptosis by activating JNK/Nrf2 survival signals in macrophages, Oxid. Med. Cell. Longev. 2015 (2015) 11, https://doi.org/10.1155/2015/351827.

[70] M.Y. Yang, C.N. Huang, K.C. Chan, Y.S. Yang, C.H. Peng, C.J. Wang, Mulberry leaf polyphenols possess antiatherogenesis effect via inhibiting LDL oxidation and foam cell formation, J. Agric. Food Chem. 59 (2011) 1985-1995, https://doi.org/10. 1021/jf103661v [doi].

[71] H. Scholz, P. Aukrust, J.K. Damas, S. Tonstad, E.L. Sagen, S.O. Kolset, C. Hall, A. Yndestad, B. Halvorsen, 8-isoprostane increases scavenger receptor A and matrix metalloproteinase activity in THP-1 macrophages, resulting in long-lived foam cells, Eur. J. Clin. Invest. 34 (2004) 451-458, https://doi.org/10.1111/j.1365-2362. 2004.01376.x.

[72] F.M. Daray, J.R. Colombo, J.R. Kibrik, A.E. Errasti, F.G. Pelorosso, W. Nowak, J.L. Cracowski, R.P. Rothlin, Involvement of endothelial thromboxane A2 in the vasoconstrictor response induced by 15-E2t-isoprostane in isolated human umbilical vein, Naunyn-Schmiedeberg's Arch. Pharmacol. 373 (2006) 367-375, https://doi. org/10.1007/s00210-006-0074-1.

[73] S.J. Hwang, Y.W. Kim, Y. Park, H.J. Lee, K.W. Kim, Anti-inflammatory effects of chlorogenic acid in lipopolysaccharide-stimulated RAW 264.7 cells, Inflamm. Res. 63 (2014) 81-90, https://doi.org/10.1007/s00011-013-0674-4 [doi].

[74] J.-K. Kim, Y.-I. Kwon, H.-D. Jang, Anti-inflammatory effects of catechol and ferulic acid derivatives through NF-kB activation in Raw264.7 cells (830.21), Faseb. J. 28 (2014), http://www.fasebj.org/content/28/1_Supplement/830.21.abstract.

[75] S. Puangpraphant, M.A. Berhow, K. Vermillion, G. Potts, E. Gonzalez de Mejia, Dicaffeoylquinic acids in Yerba mate (Ilex paraguariensis St. Hilaire) inhibit NFkappaB nucleus translocation in macrophages and induce apoptosis by activating caspases-8 and -3 in human colon cancer cells, Mol. Nutr. Food Res. 55 (2011) 1509-1522, https://doi.org/10.1002/mnfr.201100128 [doi].

[76] C.E. Morales-Martínez, A.L. Márquez-Aguirre, E. Díaz-Martínez, J.A. RodríguezGonzález, J.C. Mateos-Díaz, H. Esquivel-Solís, C. Alvarez-Moya, A.A. CanalesAguirre, Anti-inflammatory effects of p-coumaric acid in LPS-stimulated RAW264.7 cells: involvement of NF-kB and MAPKs pathways, Med. Chem. 6 (2016) 327-330, https://doi.org/10.4172/2161-0444.1000365.

[77] J. Shan, J. Fu, Z. Zhao, X. Kong, H. Huang, L. Luo, Z. Yin, Chlorogenic acid inhibits lipopolysaccharide-induced cyclooxygenase-2 expression in RAW264.7 cells through suppressing NF-KB and JNK/AP-1 activation, Int. Immunopharm. 9 (2009) 1042-1048, https://doi.org/10.1016/j.intimp.2009.04.011.

[78] J. Santana-Gálvez, L. Cisneros-Zevallos, D.A. Jacobo-Velázquez, Chlorogenic acid: recent advances on its dual role as a food additive and a nutraceutical against metabolic syndrome, Molecules 22 (2017), https://doi.org/10.3390/ molecules22030358.

[79] B.L. Dozier, K. Watanabe, D.M. Duffy, Two pathways for prostaglandin F2 $\alpha$ (PGF2 $\alpha$ ) synthesis by the primate periovulatory follicle, Reproduction 136 (2008) 53-63, https://doi.org/10.1530/rep-07-0514.

[80] T.M. Penning, Aldo-Keto Reductase (AKR) 1C3 inhibitors: a patent review, Expert Opin. Ther. Pat. (2017) 1-12, https://doi.org/10.1080/13543776.2017.1379503.

[81] N.J. Spann, L.X. Garmire, J.G. McDonald, D.S. Myers, S.B. Milne, N. Shibata, D. Reichart, J.N. Fox, I. Shaked, D. Heudobler, C.R.H. Raetz, E.W. Wang, S.L. Kelly, M.C. Sullards, R.C. Murphy, A.H. Merrill Jr., H.A. Brown, E.A. Dennis, A.C. Li, K. Ley, S. Tsimikas, E. Fahy, S. Subramaniam, O. Quehenberger, D.W. Russell, C.K. Glass, Regulated accumulation of desmosterol integrates macrophage lipid metabolism and inflammatory responses, Cell 151 (2012) 138-152, https://doi. org/10.1016/j.cell.2012.06.054.

[82] W. Fang, H. Li, L. Zhou, L. Su, Y. Liang, Y. Mu, Effect of prostaglandin E1 on TNFinduced vascular inflammation in human umbilical vein endothelial cells, Can. J. Physiol. Pharmacol. 88 (2010) 576-583, https://doi.org/10.1139/y10-028.

[83] G. Muscogiuri, L. Barrea, S. Savastano, A. Colao, Nutritional recommendations for CoVID-19 quarantine, Eur. J. Clin. Nutr. 74 (2020) 850-851, https://doi.org/10. 1038/s41430-020-0635-2.

[84] F. Naja, R. Hamadeh, Nutrition amid the COVID-19 pandemic: a multi-level framework for action, Eur. J. Clin. Nutr. (2020), https://doi.org/10.1038/s41430-0200634-3. 